\title{
EJECUTAR EN ESPAÑA LAS SENTENCIAS DEL TRIBUNAL EUROPEO DE DERECHOS HUMANOS. UNA PERSPECTIVA DE DERECHO CONSTITUCIONAL EUROPEO*
}

\author{
ENRIQUE GUILLÉN LÓPEZ \\ Profesor Titular de Derecho Constitucional \\ Universidad de Granada
}

\section{SUMARIO}

I. Introducción. II. CEDH y TEDH. Las nuevas formas de la constitucionalidad. III. Obligatoriedad, ejecutividad y eficacia de las SSTEDH. IV. Ejecutar en España las sentencias del TEDH.

\section{INTRODUCCIÓN}

El tratamiento dogmático de la ejecución de las sentencias del TEDH puede, idealmente, llevarse a cabo desde dos paradigmas: en primer lugar, cabe emprenderlo desde el punto de vista del derecho interno, esto es, reparando primordialmente en los problemas que concurren para dar cumplimiento, en este caso en el Reino de España, de una sentencia condenatoria. Desde esta perspectiva, los problemas de la ejecución de las sentencias del TEDH resultan ser sobre todo de índole procesal (o procesal-constitucional) y las páginas por redactar deberían llevarnos a reconstruir toda la secuencia hasta que en 2015 se aprueba el mecanismo previsto en la Ley Orgánica 7/2015, de 21 de julio, por la que se modifica la Ley Orgánica 6/1985, de 1 de julio, del Poder Judicial, para pasar a continuación a evaluar el nuevo sistema. Este es el paradigma que podríamos llamar clásico, en tanto que parte de la existencia de dos planos netamente diferenciados, el internacional y el interno, de naturaleza y posición desiguales, lo que aboca a una solución dada en el caso de que los conflictos se desaten ${ }^{1}$.

* Trabajo realizado en el ámbito del Proyecto de Investigación DER2016-77924-P, financiado por el Ministerio de Economía y Competitividad (MINECO). Quiero agradecer, en especial, a M. Azpitarte Sánchez y a J.F. Sánchez Barrilao, su disposición para discutir sobre las cuestiones que les he ido puntualmente trasladando. En los aciertos alcanzados tienen todas las responsabilidades. Las flaquezas son enteramente mías. Lamentablemente, el common sense al que siempre intenta conducirme el Letrado de la Junta de Andalucía, T. Requena López, no llega a hacerme suficiente mella.

1 Esta posición puede verse tras el análisis de C. Ruiz MigueL, «La STEDH sobre la doctrina Parot y el problema de la ejecución de las sentencias del TEDH», en M. PÉrez Manzano, J.A. Lascuraín Sánchez (dirs.), La tutela multinivel del principio de legalidad penal, Marcial Pons, Madrid, 2016, pp. 377-408. 
Sin embargo, la óptica que he preferido para estas páginas no es ésta sino la de trabajar este ámbito tras haber intentado configurar dogmáticamente y perfilar los diversos aspectos implicados en la ejecución de las sentencias del TEDH; esto es, tras considerar la ejecución como un aspecto parcial que debe ser contemplado en el contexto del completo sistema (normativo y jurisprudencial) de afirmación y garantía de derechos que se emprende en el Consejo de Europa ${ }^{2}$.

Tras esta opción late una convicción que muy sucintamente cabe expresar de la siguiente manera: la realidad constitucional actual — toda, pero en especial la relativa a la de los derechos - no puede ser abarcada sino considerando los contextos nacionales (incluso los constitucionales) como aspectos parciales de procesos de constitucionalización en curso ${ }^{3}$. Indiscutiblemente el constitucionalismo global está apenas esbozado ${ }^{4}$, pero no es el caso del constitucionalismo en el marco regional europeo, cuyos principales instrumentos normativos y jurisprudenciales deben entenderse como parámetro privilegiado, no solo de comprensión, sino también de definición de las respuestas constitucionales internas. En definitiva, no considero muy acertada la contemplación de las Sentencias del TEDH y su necesaria ejecución como un elemento extraño que nuestro ordenamiento constitucional debe acusar dado que hemos de cumplir con nuestras obligaciones con la comunidad internacional ${ }^{5}$. Hay, por el contrario, que partir de que nos hemos comprometido, sancionándolo en nuestra Constitución ${ }^{6}$, con una parte de la comunidad internacional en un proceso de garantía de derechos, y de que un proceso de garantía acaba inexorablemente dando lugar a un proceso de afirmación y definición de los mismos. De aquí resulta la indiscutible naturaleza constitucional del CEDH y de su Tribunal, lo que exige articular la respuesta interna en coherencia. Ello no implica, obviamente, que no se puedan deducir conflictos tal

2 Que como intentaremos plantear son aspectos solo concebibles en el seno de una teoría general sobre la obligatoriedad de sus resoluciones.

3 Procesos que estimo, de un lado, obligados, por coherencia con los que los presupuestos materiales del constitucionalismo suponen (cfr. la conexión con las palabras de R. RORTY, «La manera correcta de entender el lema $<$ Tenemos obligaciones para con los seres humanos simplemente como tales> es interpretándolo como un medio para exhortarnos a que continuemos intentando ampliar nuestro sentimiento de <nosotros $>$ tanto como podamos. Este lema nos incita a continuar extrapolando en la dirección a la que llevaron determinados acontecimientos del pasado: la inclusión entre < nosotros > de la familia de la caverna de al lado, después de la de la tribu del otro lado del río, después, la de la confederación de tribus del otro lado de la montaña, más tarde la de los infieles del otro lado del mar (y, acaso, al final de todo, la de los servidores que, durante todo ese tiempo, han estado haciendo la parte más sucia del trabajo)», Contingencia, ironía y solidaridad, Paidos, Barcelona, 1991, p. 214); y de otro, necesarios, en cuanto que su clausura en las fronteras estatales representará el fracaso en un entorno globalizado con actores cada vez más pujantes. En este sentido creo que se puede acoger el concepto de constitución-red (cfr. el esclarecedor trabajo de R. BUSTOS GISBERT, La constitución red: un estudio sobre supraestatalidad y constitución, IVAP, Oñati, 2005) que va sumando nudos.

4 A. Peters, «The Merits of Global Constitutionalism» disponible en https://www.repository.law.indiana. edu/cgi/viewcontent.cgi? referer =https://www.google.es/\&httpsredir = 1\&article=1396\&context=ijgls

5 Esta perspectiva es la que puede comprobarse en ciertas manifestaciones de la opinión pública cuando la sentencia condenatoria remueve ciertas sensibilidades (Caso Del Río Prada c. España de21 de octubre de 2013). Una muestra indicativa de las reacciones se puede encontrar en http://www.lne.es/noticias-hoy/reacciones_parot.html

6 Muy atinadas son las palabras de Requejo «Como norma del Derecho internacional integrada en el Ordenamiento interno, el Convenio Europeo de 1950 forma parte del Derecho español con el mismo título que cualesquiera de las normas elaboradas a través de los cauces de producción normativa directamente establecidos y regulados por la Constitución. Atribuir efectos jurídicos a las resoluciones emanadas de los órganos establecidos por tal Convenio no es, pues, resultado de una imposición ajena a nuestro Ordenamiento, ni es preciso explicar dicha atribución en términos de concesión o, si se quiere, de condescendencia». Cfr. J.L. REQUEJo PAGÉs «La articulación de las jurisdicciones internacional, constitucional y ordinaria en la defensa de los derechos fundamentales: (a propósito de la STC 245/91 «Caso Bultó»)», REDC, n. ${ }^{\circ}$ 35, 1992, p. 182. 
y como ocurre con el reconocimiento de derechos estatutarios ${ }^{7}$ sino tan solo que en su resolución la norma suprema — que en 1978 lo fue de forma exclusiva y excluyente (sin Estatutos que integraran el bloque de la constitucionalidad; sin organización supranacional que ejerciera competencias derivadas de la Constitución; sin Convenio Europeo de Derechos Humanos $\left.^{8}\right)$ — debe asumir que la respuesta constitucional ya no está solo en la Constitución formal ${ }^{9}$. Esta es la perspectiva del Derecho constitucional europeo ${ }^{10}$.

\section{CEDH Y TEDH. LAS NUEVAS FORMAS DE LA CONSTITUCIONALIDAD}

\section{CEDH y TEDH. Materia y forma constitucional}

La perspectiva metodológica del Derecho constitucional europeo parte de los inexorables cambios que se han producido en los modelos jurídico-políticos en los Estados que en el contexto europeo posterior a la Segunda Guerra Mundial emprendieron el inaudito camino de despojarse de ámbitos tradicionalmente tenidos por soberanos. En estos, y tras su periplo, la Constitución ya no es no es reconocible bajo la forma de instrumento normativo preciso y excluyente que es aprobado en su seno por el llamado poder constituyente como expresión de una soberanía inalienable ${ }^{11}$. La desconexión entre Constitución y estatalidad es una realidad jurídica indiscutible fácilmente comprobable cuando ponemos el foco en los descriptores primarios del primer término: derechos fundamentales; sistema de órganos y forma de gobierno; sistema de fuentes; distribución de competencias entre las diferentes entidades territoriales; y jurisdicción constitucional. Ninguno de estos aspectos puede confinarse en un estudio exclusivamente estatal.

Pero ciertamente, la deslocalización estatal de la materia constitucional solo es concebible en el seno del proceso histórico de control del poder y aseguramiento de los derechos de las personas ${ }^{12}$, si las estructuras de destino son estructuras constitucionales. Solo es pensable que una comunidad se desposea de soberanía porque ésta se entiende una

7 Sobre la densidad constitucional de esta opción el utilísimo el fecundo debate en el que intervinieron de forma muy destacada. F. CAAmaño Domínguez «Sí, pueden: (declaraciones de derechos y Estatutos de Autonomía)», REDC n. ${ }^{\circ}$ 79, 2007, págs. 33-46; y L.M. DíEz-PicAzo GimÉnEz, «De nuevo sobre las declaraciones estatutarias de derechos: respuesta a Francisco Caamaño», REDC, n. ${ }^{\circ} .81$, pp. 63-70

8 Recordemos que su instrumento de ratificación data del 26 de septiembre de 1979.

9 P. Cruz Villalón, «El espacio constitucional europeo» en La constitución inédita. Estudios ante la constitucionalización de Europa, Trotta, Madrid, 2004.

10 P. Haberle, «Derecho Constitucional Común Europeo», Revista de Estudios Políticos, 1993, n. ${ }^{\circ}$ 79. Cfr. tb. A. Barrero Ortega, «La metamorfosis del Título I a causa del Derecho constitucional europeo», en F. ReviRIEGo PICón (coord.) Constitución y globalización. Transformaciones del Estado constitucional, Fundación Giménez Abad, Zaragoza, 2013; y E, GuILlÉN LóPEZ, «Metodología del Derecho constitucional europeo. Un Derecho constitucional para la integración política de Europa. Del pluralismo territorial al pluralismo ideológico», Revista de Derecho constitucional europeo, n. ${ }^{\circ}$. 12, 2009, pp. 151-170

11 Sobre la reelaboración del concepto de Constitución Resulta Ser Una Aproximación Sintética Pero Extraordinariamente Aguda La De F. Rubio LloRente en «El constitucionalismo contemporáneo» (REDC, n. 105) en la que recensiona críticamente los trabajos de Petra Dobner y Martin Laughin (eds.), The Twilight of Constitutionalism (Oxford University Press, 2010), y Alexander SOMEK, The Cosmopolitan Constitution (Oxford University Press, 2014).

12 Siempre el artículo 16 de la Declaración de Derechos del Hombre y del Ciudadano. 
noción caduca para el progreso jurídico, económico y social del Pueblo que constituye su dimensión constitutiva; para la mejora de sus índices de libertad e igualdad. Dicho muy llanamente: la soberanía estatal puede ser contingente; los principios constitucionales, no. El constitucionalismo ha de trascender, entonces, de la constitución nacional. Podríamos perder - y de hecho los hemos perdido - algunos de los atributos que tradicionalmente han definido al Estado, pero una paralela carencia de las esencias de lo que el constitucionalismo ha venido proponiendo desde su origen supondría mucho más que un retroceso histórico.

En Europa, tras la Segunda Guerra Mundial, se inició un proceso orientado a esta trascendencia. De una forma cautelosa, evolutiva, se arbitraron instrumentos para que derechos y economía (razón e interés, podríamos decir, si se nos permite la paráfrasis del texto de Hirschmann ${ }^{13}$ ), entre sí, y entre las primigenias realidades estatales, se fueran progresivamente hibridando. Las estructuras creadas a tal fin fueron el Consejo de Europa y las Comunidades Europeas, que surgen así como estructuras nacidas para «devenir», no concluidas; nacen como proyectos para lograr una Unión más estrecha entre los Estados Miembros (Preámbulo del CEDH) ${ }^{14}$. Su ambición fue colmándose merced a una ayuda inestimable, que suponía su separación definitiva de cuantos intentos les habían precedido. Nos referimos al derecho. Consejo de Europa y Comunidades Europeas, cada una con sus singularidades, no se quedaron en una mera propuesta política o sedicentemente jurídica. Se dotaron de textos realmente normativos, el CEDH y los Tratados constitutivos, respectivamente, que admitían lecturas rotundamente afirmadoras de su eficacia. La realidad debía ajustarse a una nueva norma; unas nuevas normas alumbraban una realidad diferente. No se trataba, pues, de establecer unas pautas orientadoras a las que los poderes de los Estados miembros hubieran buenamente de aproximarse. Por el contrario, se perseguía impedir que una norma estatal no desplegara efectos cuando fuera contradictoria con el parámetro que CEDH y Tratados constitutivos representaban. Y esta es la funcionalidad del TEDH y del TJUE, como órganos indiscutiblemente jurisdiccionales, que velan por el cumplimiento de los textos ${ }^{15}$ en los que se han concentrado los márgenes en los que puede actuar el Estado. Los Estados miembros del Consejo de Europa no pueden establecer la pena de muerte ${ }^{16}$. Los miembros de la UE ven impedido el socialismo de estado. Los Tribunales, la lógica jurisdiccional, presta un servicio a esta causa que ha permitido caracterizar en torno a ella todo un estadio evolutivo del nuevo constitucionalismo ${ }^{17}$.

Nos encontramos, pues, en una nueva era que se inaugura para el derecho en el marco regional europeo; una nueva era con muchos flancos y desafíos a los que en esta sede no podemos hacer referencia. Seguramente el principal sea el que, desde el punto

13 A. O. Hirschman, Las pasiones y los intereses. Argumentos políticos en favor del capitalismo previos a su triunfo. Capitán Swing, 2014.

14 La importancia del Preámbulo está bien ponderada en J. García RocA, «El Preámbulo contexto hermeneútico del Convenio: Un instrumento constitucional del orden público europeo» en J. García Roca, P. SANTAOLALla (Coords.), La Europa de los Derechos. El Convenio Europeo de Derechos Humanos, CEPC, Madrid, 2005, pp. 21 y ss.

15 Realmente van mucho más allá de su cumplimiento. Cfr. F. BALAguer Callejón, «Los tribunales constitucionales en el proceso de integración europea», Revista de Derecho constitucional europeo, n. . 7, 2007.

16 Tras su abolición absoluta en el Protocolo n. ${ }^{\circ} 13$

17 Cfr. J. L. Weiler, «Viaje a lo desconocido: pasado y futuro del Tribunal de Justicia en el campo de la integración política», en Europa, fin de siglo, CEC, Madrid, 1995. 
de vista político quiere hacer jurídicamente posible el sueño nostálgico de la soberanía estatal $^{18}$, la exclusiva consideración constitucional de las normas que ocupan la posición suprema de cada ordenamiento; atribuir el marbete de constitucional solo al Tribunal de Karlsruhe. Por el momento es un sueño político. La teoría y la práctica jurídica ya han acusado rigurosamente los cambios producidos, por la acción fundamentalmente de la UE.

Pero seguramente hay que insistir todavía más en lo que suponen el CEDH y el TEDH, que se separan de la realidad de la Unión, a mi juicio, por dos hechos fundamentales: el primero por la naturaleza de su objeto. Los derechos fundamentales son, de un lado, normas jurídicas definitorias de un determinado modelo individual y social de convivencia $^{19}$; y de otro, normas que aspiran a tener eficacia directa ${ }^{20}$. De acuerdo con el primero cualquier intervención «foránea» en los derechos que dé un contenido que diverja respecto del que la comunidad política nacional entiende como más ajustado a sus peculiaridades estará en el disparadero. Para quienes la critican, un buen argumento será seguir encastillando la doctrina del tribunal que nos condene en la categoría de «internacional».

Por otro lado, la definición de los derechos fundamentales lleva al concepto de eficacia directa, tanto mas cuanto que se trata de derechos y libertades clásicos. En este sentido un texto sobre derechos no requiere un ordenamiento sobre derechos; exige, primordialmente, ontológicamente, que el ordenamiento no vulnere los derechos ${ }^{21}$. Sin embargo, un texto que establezca libertades de alcance económico necesita de un conjunto normativo de desarrollo que se imponga en el momento aplicativo sobre el derecho de los Estados miembros. Desde este punto de vista la UE ha podido afirmarse en toda su contundencia en la categoría de la aplicabilidad y no en la de validez ${ }^{22}$. No ha podido hacerse tal cosa en el ámbito del Consejo de Europa.

El segundo aspecto que ha de ser tenido en cuenta para cualificar la posición del CEDH y del TEDH respecto de la compacta realidad que constituye la Unión es la desigual posición jurídica de los Estados miembros del Consejo de Europa. Resulta de extraordinaria importancia resaltar que mientras algunos son también miembros de la UE, otros no. Para los primeros, el proceso de interiorización constitucional de la UE viene a suponer un indiscutible proceso de constitucionalización del CEDH y del TEDH (vía art. 6 TUE, de la entera CDFUE y, específicamente, del art. 52) ${ }^{23}$. En cambio, todavía los segundos pueden

18 Un sueño en sentido contrario es el que pretende hacer constituir un nuevo soberano a escala continental, «lo que supone sobreponerse a su obsesión por el límite y administrarla en beneficio de un crecimiento ordenado y sostenible en términos de garantía de la libertad individual». Cfr. J.L. ReQUejo PAGÉs, El sueño constitucional, KRK Ediciones, Oviedo, 2016. La cita es de la página 265.

19 También lo hace la economía, y seguramente de manera más profunda, pero su intervención es más silente

20 Cfr. J. Jiménez Campo, Derechos fundamentales. Concepto y garantía, Trotta, Madrid, 1999. P. Cruz VillaLón, «Formación y evolución de los derechos fundamentales», REDC, n. ${ }^{\circ}$ 25, 1989, págs. 35-62.

21 Sobre todo cuando los derechos son de raigambre liberal clásica.

22 Un papel muy definitorio tiene este argumento en la obra de REQUEJo. Cfr. El sueño constitucional, op.cit. (esp. pp. 136 y ss) Una condensación es la frase de la página 137: «La validez aboca indefectiblemente a la incomunicación entre ordenamientos».

23 «Legal scholars have for long now spoken of the Convention as a «constitutional instrument of European public order». In examining individual petitions after all domestic remedies are exhausted, a domain customarily reserved to constitutional law, the ECHR resembles less an international tribunal and more a court of final appeal. Over the past couple of years, the Court's initiative in ordering states to undertake structural 
poner una soberanía de la que los primeros carecen como justificación para incumplir con obligaciones, que para ellos son indiscutible y meramente internacionales ${ }^{24}$.

Es por ello por lo que las páginas que siguen se refieran al CEDH y al TEDH tal y como han de ser concebidos en el seno de la comunidad de Estados Miembros de la UE a la que España pertenece.

Como cabe predecir de lo anterior, a mi juicio no deben caber muchas dudas de la naturaleza constitucional tanto del Convenio como del Tribunal. Son respectivamente, un texto normativo y un órgano jurisdiccional, que comparten algunas de las notas definitorias propias de lo que la constitucionalidad significa a estas alturas del siglo $\mathrm{xxI}^{25}$. Así, enuncian auténticos y efectivos límites a los poderes estatales ${ }^{26}$; reconocen unos derechos vinculados directamente a la dignidad humana ${ }^{27}$; preservan la democracia ${ }^{28}$; el Estado de derecho; sin dejar de llevar a los derechos y libertades que reconocen a un ámbito que excede con mucho el que habitualmente se le atribuye como propio ${ }^{29}$.

measures in order to redress the systemic causes of human rights infringements (the so called «pilot» judgements) has been seen to strengthen its law-making and constitutional propensities. Further reinforcing its European quasi-constitutional qualities is the fact that the Convention system has in practice become slowly incorporated into and intricately fused with the legal and governance structures of the EU». Cfr. D. ANAGNOstou, «Untangling the domestic implementation of the European Court of Human Rights' judgments» en D. ANAGNOstou (ed.), The European Court of Human Rights. Implementing Strasbourg's Judgements on Domestic Policy, Edinburgh University Press, Edimburgo, 2014, p. 5.

24 El caso de Rusia es uno de los más notorios. Obsérvese si no la siguiente declaración del Tribunal constitucional ruso según se recoge con mucha preocupación en Mise en œuvre des arrêts de la Cour européenne des droits de l'homme, Rapport de l'Assemblée parlementaire du Conseil de l'Europe (Rapporteur Pierre-Yves Le Borgn), Consejo de Europa, Estrasburgo, 2017. (p. 34): «Le 14 juillet 2015, la Cour constitutionnelle russe a publié une déclaration précisant que « la participation de la Fédération de Russie à un traité international ne signifie pas son renoncement à la souveraineté nationale. Ni la Convention européenne des droits de l'homme, ni les positions judiciaires adoptées par la Cour européenne des droits de l'homme sur son fondement ne peuvent annuler la primauté de la Constitution. Leur mise en œuvre concrète dans l'ordre juridique russe est soumise exclusivement à la reconnaissance de la suprématie du caractère juridiquement contraignant de la Constitution »90. Par la suite, un amendement à la loi constitutionnelle fédérale a été adopté par la Douma d'État le 4 décembre 2015 et approuvé par le Conseil de la Fédération le 9 décembre 201591; selon ce texte, la Cour constitutionnelle est habilitée à déclarer «non exécutables » les décisions de juridictions internationales (dont la Cour européene des droits de l'homme) au motif de leur incompatibilité avec les « fondements de l'ordre constitutionnel de la Fédération de Russie » et « avec le régime des droits de l'homme instauré par la Constitution de la Fédération de Russie ».

25 Resulta ser un análisis muy sugestivo el que a la altura de 2001-2002 pergeña P. Cruz Villalón y que con el título «La Constitución inédita. La dificultad del debate constitucional europeo» está actualmente incluido en La Constitución inédita. Estudios ante la constitucionalización de Europa, op. cit. En particular, conviene resaltar la vigencia que sigue otorgando a la constitucionalidad «como estado o forma de ser de la comunidad política» (p. 39). En el presente trabajo se toman nota de las transformaciones que tanto operadores jurídicos como ciudadanos han experimentado recientemente lo que nos lleva a mantener que dicha característica forma parte de una constitucionalidad de máximos, pero no de toda la constitucionalidad.

26 A la espera de que consigan hacerlo también con la Unión cuando se alcance la prometida adhesión ex art. 6.2 TUE.

27 Sobre el lugar de la dignidad humana en el CEDH pese a su mínima presencia literal (solo se encuentra mencionada en el Protocolo n. ${ }^{\circ}$ 13) cfr. A. Elvira Perales, «La dignidad humana en el Tribunal Europeo de Derechos Humanos» en R. CHUECA (dir,), Dignidad humana y derecho fundamental, Madrid, 2015, pp. 197-233.

28 Fundamentalmente al garantizar el libre juego político a través de derechos como los de participación política. Es de interés recordar como desde los primeros textos inspiradores una de las ideas era preservar la capacidad de la oposición política para convertirse en alternativa de gobierno.

29 Cfr. por ejemplo, la conexión entre el medio ambiente y la intimidad domiciliaria al plantear de la manera en que lo hace la contaminación acústica o por ruidos. Cfr. Mathews c. Reino Unido de 18 de febrero de 1999. 
Es en este sentido que han de interpretarse pronunciamientos como el del TEDH en el caso Loizidou contra Turquía de 23 de marzo de 1995 cuando señala en su parágrafo 75 que el Convenio es el «instrumento constitucional del orden público europeo» ${ }^{30}$. A partir de esta concluyente observación habría que señalar con Greer y Wildhaber que aquellos que niegan tal sustancia tendrían que concluir que el TEDH no ha asumido correctamente la naturaleza del texto que protege ${ }^{31}$.

En nuestra opinión, sin embargo, el TEDH ha comprendido muy bien (seguramente demasiado bien para algunos) las detonación jurídica que ha supuesto en el marco regional europeo un texto llamado, no a declarar derechos, sino a garantizar derechos ${ }^{32}$. El CEDH es el punto inicial de una narrativa del constitucionalismo cifrada en la

También y muy señaladamente las condenas al Reino de España en López Ostra (STEDH de 9 de diciembre de 1994) y Moreno Gómez (STEDH de 16 de noviembre de 2004)

30 Reiterado, por ejemplo en la Sentencia Al-Skeini y otros c. Reino Unido de 17 de julio de 2011. Cfr. Más allá aún van ciertos pronunciamientos como los del Juez Pinto de Alburquerque en el Voto particular concurrente (al que se unen los jueces Hajiyev, Pejchal y Dedov) dictado con ocasión de la sentencia Dulimi y Montana Management Inc. C. Suiza de 21 de junio de 2016:

«59. Le Conseil de l'Europe est un ordre juridique autonome fondé sur des accords et sur une action commune dans le domaine économique, social, culturel, scientifique, juridique et administratif ainsi que dans la sauvegarde et le développement des droits de l'homme et des libertés fondamentales (article 1, paragraphe b, du Statut du Conseil de l'Europe de 1949). Avec plus de 217 traités, l'ordre juridique de cette organisation internationale a à son sommet un traité international, la Convention européenne des droits de l'homme qui a un effet direct et supra-constitutionnel sur les ordres juridiques nationaux des États membres du Conseil de l'Europe[112]. Étant plus qu'un simple accord multilatéral sur des obligations réciproques d'États parties, la Convention crée des obligations pour les États parties envers toutes les personnes et entités privées relevant de leur juridiction. Avec son rôle de vecteur de transformation proclamé avec emphase dans le préambule qui lui donne vocation à construire une union plus étroite des États européens et pour développer les droits de l'homme sur une large base paneuropéenne, la Convention n'est ni subordonnée aux règles constitutionnelles nationales, ni aux prétendues règles supérieures du droit international, puisque c'est le droit suprême du continent européen[113]. Dans la hiérarchie de normes interne au Conseil de l'Europe lui-même, le droit des Nations unies équivaut à tout autre accord international et est subordonné à la primauté de la Convention en tant qu'instrument constitutionnel de l'ordre public européen[114].

60. De là découle la nature de la Cour en tant que Cour constitutionnelle européenne, dont les arrêts ont un effet erga omnes res interpretata qui va au-delà de leur effet inter partes res judicata, ainsi qu'un effet prescriptif puissant qui va bien au-delà de ses effets purement déclaratoires mentionnés fréquemment. Les procédures d'arrêts pilotes et quasi pilotes sont typiquement des instruments de contrôle constitutionnel, qui jouent un rôle central dans le redressement de dysfonctionnements du droit national ou la non-réglementation par le législateur en présence de dysfonctionnements systémiques[115]. Si besoin est, dans le dispositif de ses arrêts, la Cour exerce un pouvoir d'annulation indirect à travers des injonctions faites en vertu de l'article 46 en demandant à l'État défendeur à réviser ses lois, règlements administratifs et pratiques. Même si elle ne l'a pas encore utilisée, la Cour a également la compétence pour exercer une action en violation (article $46 \S 4$ de la Convention). Finalement, elle a compétence sur sa propre compétence (Kompetenzkompetenz), qui n'exclut pas, en cas de blocage politique de la procédure d'exécution et de l'action en violation au niveau du Comité des ministres, qu'elle accepte de jouer un rôle de supervision concernant l'inexécution ou l'exécution incomplète d'un arrêt de la Cour, même en l'absence d'une telle action en violation. C'est enfoncer une porte ouverte aujourd'hui que de dire que le mécanisme d'exécution essentiellement intergouvernemental a radicalement changé de nature de par le rôle prépondérant que la Cour elle-même joue dans la garantie de l'efficacité du système de protection des droits de l'homme[116]. Le Conseil de l'Europe peut ainsi avancer une forte revendication constitutionnelle». El principal punto de desacuerdo con esta visión es, como veremos, la identificación de la constitucionalidad con la supremacía ordinamental.

31 S. Greer, L. Wildhaber , «Revisiting the Debate about 'constitutionalising' the European Court of Human Rights», HRLR 12 (2012), op. cit., p. 667

32 A. SÁrz Arnárz, «El Convenio de Roma, el Tribunal Europeo de Derechos Humanos y la cultura común de los Derechos fundamentales en Europa», en AAVV, Estudios sobre la Constitución Española. Homenaje al Profesor Jordi Solé Tura, (Volumen II), CEC, Madrid, 2008, p. 2043. 
garantía (esencialmente jurisdiccional ${ }^{33}$ ) supranacional de los derechos. Es un tratado internacional, en una reelaboración permanente dirigida a poner la protección de los derechos en la agenda de todos los Estados miembros; a que las esferas de inmunidad frente al poder de las que han de gozar las personas se revelen, al fin, como una necesidad jurídica ${ }^{34}$.

La silenciosa revolución emprendida en el seno del Consejo de Europa tiene como uno de sus puntales la transformación cualitativa que ha sufrido el $\mathrm{CEDH}$; efectivamente, según nuestro parecer ${ }^{35}$, el CEDH ha devenido una suerte de Constitución, reducida a sus elementos básicos: los derechos fundamentales; un texto constitucional que pone límites al poder y asegura ámbitos inmunes que habrán de ser reestablecidos en el caso de que sean quebrados; un texto constitucional, que tiene que justificar que se desentiende de la supremacía porque está desligado de la estatalidad ${ }^{36}$; que no es producto de un poder constituyente canónico ${ }^{37}$; y que no puede ser, por definición una síntesis perfecta de la historia de los Estados miembros porque a lo que aspira es a un futuro compartido $^{38}$.

33 Pero no solo; piénsese en la importantísima doctrina que exige a los estados miembros que en la restricción de los derechos la ley se tenga que atener a los principios de necesidad y proporcionalidad. Eso significa que el CEDH no solo descansa en el aspecto judicial del derecho sino que también condiciona el momento normativo.

34 Creo que cabe atribuir una inequívoca responsabilidad a esta narrativa en el surgimiento de la CDFUE, que desde el principio se advirtió como el producto de una necesidad. Cfr. G. Cámara Villar, «Los Derechos Fundamentales en el proceso histórico de construcción de la Unión Europea y su valor en el Tratado Constitucional», Revista de Derecho Constitucional Europeo», n. ${ }^{\circ} 4$, julio-diciembre de 2005.

35 Cfr. también A. Sárz Arnárz: «Con todos los matices que han de hacerse al empleo de estos términos podría afirmarse que tenemos tres Constituciones y tres Tribunales Constitucionales interviniendo en un mismo espacio, en un idéntico ámbito material», op. cit., p. 2047.

36 Creo que la DTC 1/2004 puede ser un buen indicativo de la forma en la que hay que entender los conceptos de supremacía y constitución en el marco de procesos de integración supranacional.

37 Como tampoco lo son desde este punto de vista textos constitucionales como el alemán. Los escurridizos perfiles del poder constituyente en este período del Derecho constitucional están trazados entre otros por F. Balaguer Callejón, «El status constitucional de la reforma y la fragmentación del poder constituyente», en La democracia constitucional : Estudios en homenaje al profesor Francisco Rubio Llorente, Vol. 1, Congreso de los Diputados, Madrid, 2002, págs. 99-130; y M. AzPitarte SánChez, «Sobre la utilidad jurídica del concepto del poder constituyente», en M.A. García Herrera, J. Asensi Sabater, y F. Balaguer Callejón, Constitucionalismo crítico. Liber amicorum Carlos de Cabo Martín, Tirant lo Blanch, Valencia, 2016, pp. 833-859. El aspecto adaptativo y ordenador de la convivencia pro futuro del Convenio puede verse también en la forma en que el TEDH lo considera un «living instrument». Cfr, «That the Convention is a living instrument which must be interpreted in the light of present-day conditions is firmly rooted in the Court's case-law (see, inter alia, the Tyrer v. the United Kingdom judgment of 25 April 1978, Series A no. 26, pp. 15-16, para. 31). Such an approach, in the Court's view, is not confined to the substantive provisions of the Convention, but also applies to those provisions, such as Articles 25 and 46 (art. 25, art. 46), which govern the operation of the Convention's enforcement machinery. It follows that these provisions cannot be interpreted solely in accordance with the intentions of their authors as expressed more than forty years ago». STEDH, Loidizou c. Turquí, de 23 de marzo de 1995 , par. 71

38 Puede verse este aspecto en las « dolientes » opiniones de algunos magistrados que siguen conectando en exclusiva la sustancia constitucional al estado nacional en tanto que depositario único de toda la historia sin la que los derechos devienen incomprensibles. Merece la pena traer a colación por su contundencia el inicio del Voto particular concurrente del Juez Bonello en la Sentencia Lautsi c. Italia de 18 de marzo de 2011: «1.1 Une cour des droits de l'homme ne saurait se laisser gagner par un Alzheimer historique. Elle n'a pas le droit de faire fi de la continuité culturelle du parcours d'une nation à travers le temps, ni de négliger ce qui au fil des siècles a contribué à modeler et définir le profil d'un peuple. Aucun tribunal supranational n'a à substituer ses propres modèles éthiques aux qualités que l'histoire a imprimées à l'identité nationale. Une cour des droits de l'homme a pour rôle de protéger les droits fondamentaux, mais sans jamais perdre de vue ceci : «les coutumes ne sont pas 
Desde este punto de vista resulta que la afirmación del TEDH en Loidizou no es una mera declaración voluntarista sino diagnóstico certero de la forma en la que el concepto de constitución ha evolucionado ${ }^{39}$; supone, en la reivindicación de la constitucionalidad de su propuesta, un avance en los principios del constitucionalismo; un reconocimiento pragmático de la fragmentariedad de este instrumento que en modo alguno ha de verse como un intento de descapitalizar (si se me permite la licencia) la posición de la constitución interna. Efectivamente, considerar el CEDH como estructura constitucional no equivale a una desvalorización de la Constitución nacional o a mantener su dilución en espacios jurídicos dominados en exclusiva por los órganos judiciales de creación y aplicación del derecho (el famoso diálogo judicial). La constitución nacional sigue representando el marco de acción para la defensa de los intereses generales (especialmente a través de los procesos electorales), el ámbito en el que se desatan los conflictos y las corrientes ideológicas los traducen en propuestas de transformación concretas ${ }^{40}$. No podemos olvidar que el espacio público continúa siendo el nacional (si bien cabe advertir un importante cambio de tendencia $)^{41}$. En la combinación entre principio democrático y Estado de derecho, la constitución nacional es el marco de la comunidad política, el espacio del debate y la legislación completa, y el CEDH el último y eventual polo de definición y garantía jurídica de los derechos fundamentales, fuente de una jurisprudencia que, como creación del derecho, es siempre fragmentaria. De este modo, se recose de una nueva manera la inquebrantable unidad entre principio democrático y Estado de Derecho. La conformación actual de nuestros sistemas jurídico-políticos lleva a que no puedan escindirse constitución nacional y realidades constitucionales extraestatales como la que representa el TEDH.

Lo que el CEDH representa en el marco jurídico europeo es incomprensible sin reparar en la importancia estructural atribuida desde su inicio — si bien progresivamente acrecentada ${ }^{42}$ - del TEDH. Efectivamente el bloque normativo que es objeto de regulación en el seno del Consejo de Europa tiene dos focos principales: los derechos y el

des caprices qui passent. Elles évoluent avec le temps, se solidifient à travers l'histoire pour former un ciment culturel. Elles deviennent des symboles extrêmement importants qui définissent l'identité des nations, des tribus, des religions, des individus ».

1.2 Une cour européenne ne doit pas être invitée à ruiner des siècles de tradition européenne. Aucun tribunal, et certainement pas cette Cour, ne doit voler aux Italiens une partie de leur personnalité culturelle ».

39 Ciertamente esta constitución parcial no comparte con el modelo de constitución normativa, del que sin duda parte, el ser el mecanismo de definición de los procedimientos de producción del resto de las normas jurídicas. Pero sí creemos que las reglas, las posibilidades y los límites de los procesos políticos y sociales en los Estados se ven muy claramente marcados por lo que el CEDH establece. Sobre la Constitución normativa como fuente del derecho continúan siendo de extraordinario interés las páginas de I. DE OTTo, Derecho constitucional. Sistema de fuentes, Ariel, Barcelona, 1988; y F. Balaguer Callejón, Fuentes del Derecho, Vol. II, Tecnos, Madrid, 1992.

40 Cfr. E. Guillén LóPEZ, «Spain. The impact of the European Convention of Human Rights and the Charter of Fundamental rights of the European Union on Spanish constitutional law: Make a virtue of necessity», en P. POPELIER, C. VAN DE Heyning y P. VAN Nuffel (eds.), Human rights protection in the European legal order: The interaction between the European and the national courts, Intersentia, Cambridge, 2011, pp. 309-342

41 P. HäBerle, «¿Existe un espacio público europeo?», Revista de Derecho Comunitario Europeo, n. ${ }^{\circ} 3,1998$, págs. 113-136.

42 Tanto normativamente, cfr. los protocolos n. ${ }^{\circ} 11,14,15$ y 16 (que ha entrado en vigor el 1 de agosto de 2018 para los Estados firmantes), como jurisprudencialmente. Sobre lo que suponen los dos últimos protocolos citados (aun no ratificados por España) cfr. L. López Guerra, «Los Protocolos de reforma n. ${ }^{\circ} 15$ y 16 al Convenio Europeo de Derechos Humanos», Civitas. Revista española de derecho europeo, n. ${ }^{\circ}$. 49, 2014, págs. 11-29. 
ordenamiento específicamente destinado a garantizar los derechos ${ }^{43}$. La pieza fundamental de éste es el TEDH como institución que «asegura el respeto de los compromisos que resultan para las Altas Partes Contratantes del presente Convenio y sus Protocolos» (art. $19 \mathrm{CEDH}$ ); cuya competencia «se extiende a todos los asuntos relativos a la interpretación y aplicación del Convenio y de sus Protocolos» (art. $32 \mathrm{CEDH}$ ); y que dicta sentencias de obligatorio cumplimiento (art. $46 \mathrm{CEDH}$ ), con el objeto de reparar perfectamente la violación del derecho en cuestión (art. $41 \mathrm{CEDH}$ ).

Este Tribunal profusamente regulado no puede, volviendo al hilo conductor de este trabajo, recibir una consideración pareja a la que se atribuye a los Comités de vigilancia de otros textos declaratorios de derechos humanos que un Estado pueda convenir con otros sujetos de derecho internacional.

Antes bien, creemos que hay suficientes razones para afirmar sin ambages su naturaleza constitucional ${ }^{44}$. En primer lugar, lo es si, como hemos afirmado, se trata del intérprete supremo de una norma de carácter constitucional. De mantenerse que el $\mathrm{CEDH}$ ejerce como fuente constitucional sobre los derechos en el marco regional europeo (específicamente en el marco en el que coinciden los Estados miembros de la UE) es de rigor concluir que el Tribunal de Estrasburgo ha de ser un tribunal en materia constitucional ${ }^{45}$.

De otro lado, el TEDH no solo tiene por objeto la materia constitucional; es que, como no puede ser de otro modo (porque la materia condiciona el razonamiento), discurre y resuelve los conflictos que se le plantean «a la manera constitucional». Y «a la manera constitucional» quiere decir que, como ha ocurrido con los tribunales internos,

43 Podría decirse así que si bien es cierto, como hemos señalado, que un texto sobre derechos no precisa de normativa de desarrollo, sí que la requiere la parte de el mismo destinada a su garantía jurisdiccional. Es así que encontramos un conjunto normativo importante (así como también de soft law) de carácter procesal tanto en Convenio como en las Reglas de procedimiento del Tribunal, así como en todo un conjunto de resoluciones de la Asamblea parlamentaria, fundamentalmente, para lograr la eficacia de las sentencias del Tribunal.

44 Entre los autores que destacan con toda claridad este aspecto resalta A. STONE SwEET, «Constitutionalism, Legal Pluralism, and International Regimes», Indiana Journal of Global Legal Studies, Volume 16, Issue 2, Summer 2009, pp. 621-645: «As an empirical matter, in comparison with all currently operating systems of constitutional review, or relative to all those that have operated over the past cen- tury, it is clear that the ECJ, the ECtHR, and the AB are among the world's more successful and effective systems of constitutional review. Each court is routinely asked to determine if and how national law and practice conflicts with treaty-de- rived law and the answers given to these questions are final. These courts rou- tinely find that some national law and acts are contrary to a state's treaty obligations. Their decisions routinely give guidance to states on how law and practice must change, and states routinely comply with these decisions». p. 642. Cfr. también J.-F. FLauss, 'La Cour européenne des droits de l'homme est-elle une Cour constitutionnelle?', Revue française de droit constitutionnel, n. ${ }^{\circ} 36,1998$.

45 Ya en 1982 y desde su particular experiencia profesional GARcía DE ENTERRía señalaba que el TEDH era un Tribunal en materia constitucional. Cfr. E. GARCía DE ENTERría, «El Derecho constitucional como derecho», Revista de Derecho político, núm. 15, 1982, p. 17. Podríamos plantearnos si en realidad es importante o no «el nombre de la cosa» pero creemos que lo es cuando en el nombre van expresas determinadas cargas de legitimidad. Y es que de la legitimidad atribuida van a depender tanto consecuencias jurídicas (por ejemplo, las que tengan que ver con la capacidad de objetar el cumplimiento de una sentencia) como políticas (en la medida en que se puedan aceptar como propia una sentencia condenatoria o por el contrario se exacerben las reacciones contrarias a la misma por ser una imposición «de fuera»). A. SAIZ señala con toda claridad «El Tribunal de Estrasburgo parece aproximarse mucho más a un tribunal constitucional de cuanto pueda estarlo a otro de carácter internacional». Cfr. «El Convenio de Roma, el Tribunal Europeo de Derechos Humanos y la cultura común de los derechos fundamentales en Europa», op. cit. , p. 2054. 
el TEDH no solo se ha ocupado de garantizar propiamente el derecho que se le ha sometido a juicio sino que se ha visto llamado a considerar, más allá de este aspecto subjetivo, el interés general del orden público europeo ${ }^{46}$. Esta es fundamentalmente la lógica más profunda que inspira la práctica de las Sentencias Piloto ${ }^{47}$.

Y no debe soslayarse que en la discusión sobre derechos el llamado test de Estrasburgo forma parte de los esquemas discursivos que los Tribunales constitucionales han acogido. Admitir que la restricción de un derecho solo puede aceptarse cuando esté prevista normativamente, sea necesaria en una sociedad democrática y observe el principio de proporcionalidad en el contexto de un modelo que reconoce un margen de apreciación nacional (equivalente al principio de presunción de la constitucionalidad de la ley en los derechos internos ${ }^{48}$ ) es muy indicativo de la dinámica obligadamente concurrente en la que se instalan los auténticos tribunales cuando se enfrentan a genuinos derechos.

Ciertamente, posición, materia y método, son solo algunos elementos para caracterizar como constitucional a un tribunal. Y no deben dejarse de lado dos posibles obstáculos de principio para admitir dicha tesis.

El primero viene apuntado desde la óptica de lo que se ha venido llamando el constitucionalismo político $\left(\right.$ Bellamy ${ }^{49}$ ). Desde este punto de vista cabría separar el TEDH de los tribunales constitucionales por el hecho de que sus sentencias no se insertan en el

46 Una sanción normativa de este cambio puede encontrarse en el Protocolo 14, que supone la modificación del art. 35 b) CEDH para quedar como sigue: «3. El Tribunal declarará inadmisible cualquier demanda individual presentada en virtud del artículo 34 si considera que:

b) el demandante no ha sufrido un perjuicio importante, a menos que el respeto de los derechos humanos garantizados por el Convenio y por sus Protocolos exija un examen del fondo de la demanda, y con la condición de que no podrá rechazarse por este motivo ningún asunto que no haya sido debidamente examinado por un tribunal nacional.» Cfr. al respecto, A. Queralt JimÉnEZ, «La protección de derechos y libertades en Europa tras la entrada en vigor del protocolo núm. 14 al CEDH», Revista española de Derecho Europeo, 36, 2010, pp. 503-506; G. CANo PALOMAR, «La existencia de un perjuicio importante como nueva condición de admisibilidad tras la entrada en vigor del Protocolo Núm. 14 al CEDH», Revista española de Derecho Europeo, 42, 2012, pp. 49-73.

47 Abrisketa Uriarte, explica bien el concepto, surgimiento y la evolución de las sentencias piloto y la gran cantidad de retos que suponen para el sistema europeo (esto es, para los Estados, los sujetos y el propio TEDH). En particular para el Estado porque le obliga a adoptar medidas generales (concretamente, modificaciones normativas) lo que es significativo de que las sentencias del Tribunal dejan de ser enteramente declarativas y lo revisten de una condición constitucional. Así lo expresa: «El procedimiento de las sentencias piloto no es pues solo una fórmula para reducir el número de demandas ante el Tribunal 37. Es aún más. Por su carácter prospectivo, el TEDH utiliza esta técnica con una visión más amplia, la de transformar su función para centrarse en los asuntos de mayor entidad (problemas sistémicos) y servir así de referente último a las autoridades nacionales (indicando las medidas generales), inspirado por la idea de construir un orden público europeo. De esta doble función (atender tanto al problema individual como al problema general) se desprenden consecuencias en lo que afecta a la naturaleza legal de las sentencias del Tribunal de Estrasburgo. A diferencia de las sentencias que no trascienden el caso singular, en las sentencias piloto del Tribunal emerge la «dimensión constitucional de sus funciones», que se analiza más adelante». Cfr. J. Abrisketa Uriarte, «Las sentencias piloto: el Tribunal Europeo de Derechos Humanos, de juez a legislador», Revista española de Derecho internacional, Vol. LXV/1, 2013, p. 82. Cfr. tb. P. LEACH, H. Hardman, S. StePHenson, B. Blitz, Responding to Systemic Human Rights Violation. An Analysis of «Pilot Judgements» of the European Court of Human Rights and their Impact at National Level, Intersentia, Antwerp, Oxford, Portland, 2010.

48 Aprecia tal similitud, muy correctamente a mi juicio, A. SAIZ ARnárz, op. cit., p. 2050. Sobre el margen de apreciación, cfr. F. J. GARCÍA RoCA, El margen de apreciación nacional en la interpretación del Convenio Europeo de Derechos Humanos: soberanía e integración, Civitas, Madrid, 2010.

49 R. Bellamy, «The Democratic Legitimacy of International Human Rights Conventions: Political Constitutionalism and the European Convention on Human Rights», The European Journal of International Law Vol. 25 no. 4, 1019-1042, 2014. Su propuesta teórica está completamente desarrollada en Constitucionalismo politico. Una defensa republicana de la constitucionalidad de la democracia Marcial Pons, Madrid, 2010. 
contexto de una opinión pública que permitan su consideración y crítica. Sin embargo, no creo que tal argumento sea enteramente asumible. Creo que cualquier acepción de constitucionalismo ha de distinguir entre la acción política y la decisión jurisdiccional a los efectos de manifestar y expresar la posición y la voluntad de la ciudadanía. Las sentencias y las acciones normativas no han de ser vigiladas con arreglo a los mismos parámetros. No es, evidentemente, una exención de la decisión judicial del eventual cuestionamiento el que se mantiene, sino la admisión de que los tribunales constitucionales han de preservar bien su dimensión ontológicamente contramayoritaria ${ }^{50}$. La determinación extra muros de la verdad judicial resulta ser una garantía constitucional a estos efectos.

Pero a ello hay que añadir que el supuesto del que la crítica parte se cumple en cada vez menor medida. Las SSTEDH tienen cada vez más eco en los procesos de debate nacionales. Es más, son, cuando las condenas recaen sobre los aspectos más sensibles de las comunidades políticas de origen, objeto de discusión colectiva (desgraciadamente a menudo teniendo como trasfondo, no el derecho, sino los intereses nacionales en la acepción - claro- que el interprete quiera darle $)^{51}$. Por lo tanto, si fuera un requisito la recepción crítica de una sentencia para afirmar la constitucionalidad del tribunal que la dicte entendemos que no tendríamos razón para negarla.

En segundo lugar, se mantiene que el TEDH está lejos de ser constitucional sobre la base de la diferencia cualitativa que media entre las sentencias de la jurisdicción constitucional y las del Tribunal de Estrasburgo ${ }^{52}$. En este sentido se insiste en que el TEDH no puede declarar la invalidez de una $l e y^{53} \mathrm{y}$, en cualquier caso, en que sus sentencias requieren para su ejecución de la actuación de los Estados. Sin embargo, creo que

50 Cfr. la supresión del recurso previo por la Ley Orgánica 4/1985, de 7 de junio, por la que se deroga el capítulo II del título VI de la Ley orgánica 2/1979, de 3 de octubre, reguladora del Tribunal Constitucional. Me parecen muy significativos los siguientes párrafos de su Exposición de Motivos: «La experiencia acumulada por más de tres años de justicia constitucional ha venido a mostrar que este recurso previo se ha configurado como un factor distorsionador de la pureza del sistema de relación de los poderes constitucionales del Estado, con consecuencias inesperadas y metaconstitucionales en la última fase de procedimiento de formación de la Ley.

El Estado configurado en la Constitución se fundamenta en un inmediato equilibrio de poderes que se caracterizan por la demarcación estricta del ámbito de actuación política y jurídica de cada uno de éstos, sin interferencias que desequilibren su relación armónica. Pero la configuración del recurso previo de inconstitucionalidad puede suponer una grave fisura en este equilibrado sistema de relaciones con incidencia negativa del Poder Legislativo y del Tribunal Constitucional».

51 De esto podemos dar cuenta en España, por ejemplo, con ocasión de las sentencias condenatorias Del Río Prada de 21 de octubre de 2013; Stern Taulat y Roura Capellera, de 13 de marzo de 2018; y Portu Juanenea y Sarasola Yarzábal de 13 de febrero de 2018. Merece la pena releer algunos editoriales y artículos de opinión de ciertos medios que representan a una corriente de opinión (y que incluyen sin consideración alguna ataques a los magistrados españoles que integran el TEDH). Cfr., por ejemplo, http://www.abc.es/opinion/abci-injusticia-europea-201802140025_noticia.html; o http://www.abc.es/opinion/abci-quemados-foto-201803161621_noticia.html

52 Se plantea la cuestión desde este punto de vista J. García Roca en «El diálogo entre el Tribunal Europeo de Derechos Humanos y los tribunales constitucionales en la construcción de un orden público europeo», Teoría y realidad constitucional, n. $^{\circ} 30,2012$, p. 212.

53 La carencia de esta competencia de revisión abstracta es a juicio de algunos autores un elemento determinante para negar que el TEDH sea un tribunal constitucional. Cfr. J. CHristoffersen «Individual and Constitutional Justice: Can the Power Balance of Adjudication be Reversed?», en Jonas Christoffersen y Mikael Rask Madsen The European Court of Human Rights between Law and Politics, Oxford, 2011, p. 202. No obstante, para completar el razonamiento cabría añadir que el TEDH puede en una demanda individual estimar que es una ley o incluso una constitución estatal (cfr. STEDH Sejdic' y Finci c. Bosnia Herzegovina de 22 de diciembre de 2009) la que ha causado la lesión del derecho, lo que supone exigir su reforma. 
tampoco son argumentos enteramente concluyentes. En primer lugar, porque los jueces de la constitucionalidad tampoco son ya siempre capaces de determinar las validez o la invalidez de las fuentes que forman parte del ordenamiento interno. Ya hemos resaltado como una de las muestras del cambio de ciclo jurídico la nueva relevancia adquirida por la aplicabilidad y la correlativa inadecuación del concepto de validez ${ }^{54}$. La conformación actual del pluralismo jurídico hace que este concepto estricto de jurisdicción constitucional ya no sea muy operativo ${ }^{55}$ debiendo decantarse por uno más amplio que integre en la categoría a los órganos plenamente jurisdiccionales que velan por la observancia de un texto en materia constitucional con argumentos que compartan estos presupuestos. La clave está, por tanto, ahora en ver si el TEDH vela jurídica, firmemente, por la CEDH con la dosis de compulsión efectiva que ha de predicarse. Y a nuestro juicio, y como veremos en el epígrafe tercero creo que hay sobradas razones para concluir que el TEDH no se limita a declarar la violación de un derecho de la CEDH sino que toda su evolución puede verse como un proceso ininterrumpido encaminado al cumplimiento de su doctrina.

Así las cosas, podríamos concluir, en nuestra opinión ${ }^{56}$, considerando al TEDH como un tribunal constitucional por su posición, por la materia sobre la que opera, por el razonamiento que sigue y por los efectos de sus sentencias ${ }^{57}$; un tribunal de un orden

54 Requejo Pagés, El sueño constitucional, op. cit.

55 Conceptos estrictos y amplios de jurisdicción constitucional respecto al TEDH se tratan adecuadamente en GREER y WILDHABER, Op. cit., pp. 670 y ss.

56 Del mismo parecer son GREER y WILDHABER, «Revisiting the Debate about 'constitutionalising' the European Court of Human Rights» (op. cit.) que enuncian cinco caracteres constitucionales del Convenio y del Tribunal. Primera: el propio Tribunal así lo establece; segunda: la discusión judicial sobre derechos fundamentales es una materia constitucional en los niveles estatales lo que hace difícil que no comparta esta cualidad cuando la discusión tiene lugar en Estrasburgo (este es quizás un argumento no muy concluyente en la medida en que no basta con que se discuta sobre derechos sino que esta discusión ha de producirse en un contexto jurisdiccional claro; por ejemplo, la discusión sobre derechos en el seno del Comité de Derechos Humanos de la ONU no basta para convertir al Pacto Internacional de Derechos Civiles y políticos en un instrumento constitucional); tercera: en numerosos estados el CEDH ha sido en alguna medida constitucionalizado lo que no resulta comprensible si esta cualidad constitucional no hubiera ya sido reconocida previamente en el nivel transnacional (la tesis que subyace podrá ser la siguiente: lo que se constitucionaliza es porque ya es materialmente constitucional...); cuarta: el TEDH decide sobre las mismas cuestiones que los Tribunales constitucionales nacionales y utiliza principios y razonamientos similares; la quinta y final característica que hace del CEDH un instrumento constitucional se refiere a que se inserta dentro de un proceso en marcha de constitucionalización general del sistema de Derechos humanos y del derecho internacional (op. cit., pp. 667-670)

57 De otro lado, y es una cuestión que solo se apunta en esta sede, el reconocimiento de la posición constitucional a un Tribunal conlleva una serie de implicaciones y consecuencias: En primer lugar, exige que se reconozca su posición como institución contramayoritaria (Cfr. M. Ahumada RuIz, La jurisdicción constitucional en Europa, Civitas, Madrid, 2005), lo que significa, en este caso, que es una institución contraestatatal, no en el sentido, obviamente, de que siempre tenga que dictar sentencias condenatorias, pero sí que debe estar presta a hacerlo. En segundo término, debería actuarse sobre dos vectores, el nombramiento de los jueces y el funcionamiento interno, para que pueda encontrarse en un tribunal compuesto por 47 jueces una línea coherente sin la cual no podría hablarse de doctrina constitucional en ningún sentido. Sobre la primera de las cuestiones, cfr. R. Bustos GisberT, «La controvertida composición y renovación de los órganos judiciales situados en la cúspide», en «Anuario de la Facultad de Derecho de la Universidad Autónoma de Madrid, en prensa (agradezco al autor habérmelo facilitado); y sobre la segunda A. Queralt Jiménez, La interpretación de los derechos: del Tribunal de Estrasburgo al Tribunal Constitucional, CEPC, Madrid, 2008, p. 38. En tercer lugar, exige un cambio de percepción del significado de la sentencia. Esto es, hay que plantearse la ejecución de las sentencias del TEDH como nos planteamos la ejecución de las Sentencias del Tribunal constitucional, cuestión que no está vinculada al hecho de que las sentencias sean a veces más afortunadas y a veces menos. Y, por último procedería, atribuirle sin más efectos 
constitucional europeo destinado a la salvaguardia última de los derechos fundamentales. Parafraseando la frase célebre de Robert H. Jackson en el caso Brown v Allen en 1953, el TEDH no es el último porque sea constitucional; es constitucional porque sobre derechos fundamentales puede ser el último (y en él reside la competencia para decidirlo así). Evidentemente hay problemas en lo que concierne a la ejecución de las sentencias de amparo, pero no son sólo específicos del $\mathrm{TEDH}^{58}$.

\section{La posición de CEDH y TEDH en el constitucionalismo complejo. El principio de subsidiariedad}

En el punto anterior hemos afirmado el carácter constitucional del CEDH y del Tribunal que vela por su cumplimiento. Sin embargo, hemos calificado como excesiva la visión del voto particular del juez Pinto do Alburquerque en la Sentencia Dulimi y Montana Management Inc. c. Suiza ${ }^{59}$ que, extrayendo conclusiones tradicionales ante un concepto nuevo, se apresta a mantener la supremacía de ambos. Y es que una idea clara a mantener como punto de partida es la necesidad de descartar el principio de supremacía o jerarquía como ordenador de las relaciones entre textos normativos e instituciones que los garantizan en el constitucionalismo complejo actual ${ }^{60}$. Lo han venido a sustituir

erga omnes con las matizaciones que a esta aseveración se hace en las normas constitucionales internas (cfr. por ejemplo el art. 164.1 CE).

Respecto de esta última cuestión, el hecho de que haya dudas en el seno del Tribunal acerca de si está deslizándose progresivamente en el sentido de atribuir efectos erga omnes a sus sentencias es ya muy significativo. Cfr. el Voto disidente del Juez Zupančič en Hutten-Czapska c. Polonia de 19 de junio de 2006: «Avons-nous véritablement élargi la portée de notre compétence au point de pouvoir prononcer désormais des arrêts ayant un effet obligatoire erga omnes et non plus seulement à l'égard des seules affaires dont nous avons directement à connaître ? Assumons-nous le rôle d'un législateur négatif pour quarante-six pays ? L'arrêt Broniowski représente-t-il réellement un saut qualitatif ?» En otro voto particular a la misma sentencia declara el juez Zagrebelsky: «Naturellement, les arrêts de la Cour ont des conséquences erga omnes sur d'autres personnes que le requérant et sur les autres Etats.» En nuestra doctrina, el carácter erga omnes de la jurisprudencia de Estrasburgo es defendido por C. MonTEsinos PADILLA, La tutela multinivel de los derechos desde una perspectiva jurídico-procesal. El caso español, Tirant Lo Blanch, Valencia, 2017, p. 176. Es interesante que GREER y WILDHABER mantienen que, entre las virtudes que tendría que el TEDH decidiera entrar a conocer de un número mucho menor de casos caracterizados por su densidad constitucional, estaría la de que podría razonar sobre ellos intensificando esta perspectiva, de manera que los efectos de sus sentencias fueran máximos tanto respecto al Estado condenado como al resto». Cfr. «Revisiting...»op. cit., p. 686.

58 Las sentencias estimatorias de amparo en nuestro modelo constitucional interno presentan también algunos puntos oscuros. Uno no menor y que tiene una conexión interesante con la doctrina del TEDH es el que se refiere a la exclusión de las consecuencias indemnizatorias de la sentencia del TC que determine la concurrencia de la lesión. Ello ha dado lugar a una polémica importante en el seno del propio TC (voto particular de Pérez Tremps al ATC 1/2009) e incluso a la condena del Reino de España por el TEDH en la Sentencia García Mateos c. España, de 19 de febrero de 2013.

59 Nota a pie n. 30.

60 «En una misma materia van a existir dos tribunales con pretensión de actuar como última instancia, sin que pueda hablarse de una relación jerárquica entre ellos, pues ciertamente, la inspiración en el Convenio Europeo de Derechos Humanos a que se refiere la Carta no implica que el Tribunal de Luxemburgo esté sometido al Convenio Europeo de Derechos Humanos ni a la jurisprudencia del Tribunal de Estrasburgo». L. LóPEz Guerra, «El Tribunal Europeo de Derechos Humanos, el Tribunal de Justicia de la UE y «le mouvement nécessaire des choses» », Teoría y Realidad Constitucional, núm. 39, 2017, pp. 163-188. La negación de la jerarquía es también uno de los presupuestos de la aproximación pluralista de N. KRISCH, Cfr. «The Open Architecture of European Human Rights Law «, LSE Law, Society and Economy Working Papers 11/2007 London School of Economics and Political Science Law Department. Por otra parte nuestro TC señalado con reiteración: que «el Convenio no ha introducido en el orden jurídico interno una instancia superior 
principios mucho más versátiles, como la primacía, por ejemplo (como criterio fundamental de resolución de controversias entre el Derecho de la UE y el de los Estados-Miembros) $)^{61}$, o el de competencia (principio que afecta tanto a las fuentes, que han de moverse en el ámbito previamente delimitado por una fuente de carácter superior, como a los órganos que dictan esas fuentes).

En el análisis del impacto de las sentencias del TEDH es fundamental reparar en uno de esos relativamente nuevos y versátiles principios: concretamente el de subsidiariedad $^{62}$. El principio de subsidiariedad significa que el sistema que se entiende subsidiario solo entra en funcionamiento una vez que el principal ha mostrado su incapacidad para resolver la controversia ${ }^{63}$. La subsidiariedad parte de una decisión constitucional de fondo a partir de la cual se establece cuál es el sistema principal y cuál aquél al que hay que recurrir en caso de default del primero. En la Constitución española (art. 53.2) se establece que la protección ordinaria de los derechos fundamentales queda encomendada al poder judicial, por ser el que dispensa la tutela judicial efectiva, y que al TC le corresponde solo de manera subsidiaria y extraordinaria intervenir zanjando la polémica ${ }^{64}$. La interpretación del órgano de control subsidiario se revela en este caso como imperativa lo

supranacional en el sentido técnico del término, de revisión o control directo de las decisiones judiciales o administrativas internas». Cfr. ATC 27/2017 FJ 2. Bien es cierto que el Reino de España al ratificar el Protocolo 14 asume lo que en el Preámbulo de éste se señala: «Considerando, en particular, la necesidad de garantizar que el Tribunal pueda continuar desempeñando su papel preeminente en la protección de los derechos humanos en Europa». (Las cursivas son, obviamente, añadidas). Esta preeminencia encaja perfectamente en la tesis de los condicionamientos mutuos propios de la constitución red tal y como es descrita por R. BUSTOS: «las normas constitucionales nacionales no son reformadas o derogadas por las normas constitucionales europeas porque no se encuentran en una relación de superioridad jerárquica. Sin embargo, sí generan transformaciones generalizadas respecto a su concreto contenido normativo. Del mismo modo, las normas constitucionales nacionales condicionan el ordenamiento constitucional supraestatal que ha de asumir los contenidos básicos de aquellas, si desea avanzar en su desarrollo como ente constitucional autónomo». Op. cit., p. 182.

61 También mantiene la primacía de la interpretación de la doctrina del TeDH J. García MurCia: «Virtualidad en el ordenamiento laboral de la jurisprudencia del Tribunal Europeo de Derechos Humanos», Actualidad Laboral, n. ${ }^{\circ}$ 6, Sección Estudios, Junio 2014, pág. 647, tomo 1, Editorial Wolters Kluwer. LA LEY 2813/2014. Concretamente señala: «Es verdad que ese carácter vinculante de la doctrina del TEDH no cuenta con una afirmación normativa directa y de carácter general, y que no existe en este terreno una proclamación del principio de primacía en términos tan explícitos e intensos como ocurre en el Derecho de la Unión Europea respecto de los sistemas nacionales . Pero la vinculación puede sustentarse sin mayor dificultad en varios pasajes de su principal norma reguladora. En primer término, en la fuerza obligatoria que se atribuye a las sentencias del TEDH, que va acompañada de un deber expreso de acatamiento para las Partes Contratantes (art. $46 \mathrm{CEDH}$ ). En segundo término, de los compromisos asumidos por los Estados miembros mediante la firma del CEDH, que impone el reconocimiento de su tabla de derechos y libertades (art. 1 CEDH). En tercer lugar, de los propios fines del Convenio y del Consejo de Europa, que residen en esencia en la creación de un «orden público europeo» en materia de derechos humanos (como cabe deducir del preámbulo del CEDH . Finalmente, del poder jurisdiccional atribuido al TEDH, que le permite conocer de demandas interpuestas contra los actos estatales que se aparten de los derechos y libertades reconocidos en el CEDH (arts. 33 y 34 CEDH), no sólo tal y como se encuentran formalmente enunciados, sino también tal y como los aclara y concreta el TEDH».

62 J. F. SÁNCHEz BARRILAO, «Constitución y relaciones entre ordenamientos en el contexto de la globalización» Estudios Constitucionales, n. ${ }^{\circ}$ 2, 2014, pp. 79-82.

63 Artículo $13 \mathrm{CEDH}$ : «Toda persona cuyos derechos y libertades reconocidos en el presente Convenio hayan sido violados tiene derecho a la concesión de un recurso efectivo ante una instancia nacional, incluso cuando la violación haya sido cometida por personas que actúen en el ejercicio de sus funciones oficiales». Artículo 35.1 CEDH: «Al Tribunal no podrá recurrirse sino después de agotar las vías de recursos internas, tal como se entiende según los principios de derecho internacional generalmente reconocidos y en el plazo de seis meses a partir de la fecha de la decisión interna definitiva».

64 Sobre todo por la forma en la que se ha configurado el amparo, tras la modificación de la LOTC de 2007 (LO 6/2007). 
que completa el sentido de la subsidiariedad: el órgano principal lo es, y el órgano subsidiario opera de cierre del sistema. De ninguna jerarquía puede, pues, hablarse.

En el ámbito del sistema europeo de protección de los derechos fundamentales estamos ante una situación parecida ${ }^{65}$. Aquí el mecanismo principal es el interno y el subsidiario el del $\mathrm{CEDH}^{66}$. Ello significa dirigir todos los esfuerzos a que los recursos internos sean los que protejan los derechos reconocidos en el Convenio (sobre la base de un principio constitucional de primer orden expresado en la idea de que los órganos nacionales son los que tienen mejor conocimiento de los problemas que están en la base de la demand $a^{67}$ ) y a su vez fortalecer que cuando estos recursos fallan la sentencia condenatoria sea ejecutada ${ }^{68}$.

La subsidiariedad es, así, el principio a partir del cual entender el sistema establecido por el CEDH, pero hay que considerarlo en la lógica de la eficacia del Convenio (tal y como la subsidiariedad se establece en la CE para la mejor garantía de los derechos fundamentales) lo que quiere decir que su valoración deberá hacerse una vez comprobado el servicio que preste a la protección y la garantía de los derechos reconocidos en el texto. La subsidiariedad resulta, pues, un criterio funcional para lograr que los derechos sean disfrutados por sus titulares; no una regla hábil para afirmar eventualmente la posición del Estado -parte en el contexto de tensión que puede abrirse con ocasión de una sentencia condenatoria. Esta es la razón por la que ha sido tan críticamente acogida por parte de la doctrina (y por parte del propio TEDH) ${ }^{69}$ la previsión contemplada en el Draft de la reciente Declaración de Copenhague (12 y 13 de abril de 2018) que, tras afirmar la importancia de la subsidiariedad añade por vez primera que los derechos han de ser protegidos de forma prioritaria por las instituciones estatales en el nivel nacional de acuerdo con sus tradiciones constitucionales y a la luz de sus particulares circunstancias

65 Greer y Wildhaber señalan que considerar al TEDH como un TC no implica establecer entre el primero y los supremos interpretes de la constitución interna unas relaciones antagonistas (de manera tal que el TEDH amenace la independencia de los TCs) sino complementarias, (Cfr. «Revisiting the Debate about 'constitutionalising' the European Court of Human Rights», op. cit., p. 675.

66 Son incontables las ocasiones en las que los textos del Consejo de Europa invocan la subsidiariedad como clave de bóveda del sistema. Así comienza por ejemplo el «Rapport annuel 2017 de la Cour européenne des droits de l'homme, Conseil de l'Europe» (disponible en https://www.echr.coe.int/Pages/home.aspx?p=court/ annualreports\&c=fre\#n14605554480264262933801_pointer).

67 Idea que se reproduce perfectamente en el concepto de margen de apreciación. De hecho ambas nociones figuran conjuntamente en el Protocolo n. ${ }^{\circ} 15$ al CEDH (pendiente de ratificación por España) cuya voluntad es que el artículo 1 del CEDH figure con el siguiente tenor: «Affirming that the High Contracting Parties, in accordance with the principle of subsidiarity, have the primary responsibility to secure the rights and freedoms defined in this Convention and the Protocols thereto, and that in doing so they enjoy a margin of appreciation, subject to the supervisory jurisdiction of the European Court of Human Rights established by this Convention.»

68 Este fue el norte, en efecto, del Informe del Grupo de Sabios, presidido por G.C. Rodríguez Iglesias, que se creo a efectos de «examinar la cuestión de la eficacia a largo plazo del mecanismo de control del CEDH, incluidos los efectos iniciales del Protocolo núm. 14 y demás decisiones adoptadas en mayo de 2004». Cfr. G.C. Rodríguez IGLesias, «¿Qué hacer para asegurar la eficacia del sistema de control judicial del Convenio europeo de Derechos Humanos? Las propuestas del grupo de sabios», Revista española de Derecho Europeo, n. . . 22, 2007, pp. 177-185.

69 https://www.echr.coe.int/Documents/Opinion_draft_Declaration_Copenhague\%20ENG.pdf. Concretamente señala: «However, the Court has concerns in particular in relation to the wording of paragraph 14 of the draft declaration. It considers that the references in this context to «constitutional traditions», and even more so to «national circumstances», may give rise to confusion. While both elements may be relevant in assessing whether a State has complied with the Convention in a particular case, that is ultimately for the Court itself to determine, as it has constantly stated in its case-law». Par. 10 de la opinión que hizo pública el 19 de febrero de 2018. 
nacionales ${ }^{70}$. Afortunadamente en su versión definitiva tal referencia, que en una lectura parcial podría dar alas a los Estados reluctantes al cumplimiento de las sentencias condenatorias $^{71}$ ha desaparecido ${ }^{72}$.

En definitiva, la subsidiariedad es un principio funcional que decae cuando deja de serlo para lograr la eficacia de lo prescrito en el Convenio. La deriva de la satisfacción equitativa del artículo $41 \mathrm{CEDH}$ es una muestra perfecta de lo que se refiere: vinculada literalmente a los supuestos en los que el Estado solo puede imperfectamente reparar la lesión, ahora es determinada al margen de esta circunstancia por el $\mathrm{TEDH}^{73}$. Esta visión instrumental de la subsidiariedad es la que impregna las páginas que siguen.

70 Parágrafo 14: «Affirms the importance of securing the ownership and support of human rights by all people in Europe, underpinned by those rights being protected predominantly at national level by State authorities in accordance with their constitutional traditions and in light of national circumstances».

71 Piénsese, por ejemplo, que la especificación del marco constitucional interno como marco desde el que determinar cómo han de ser protegidos los derechos humanos pondría en serios apuros la posibilidad de que el TEDH entendiera que es precisamente ese marco constitucional el que implica la lesión de algunos de los derechos reconocidos en el Convenio (tal es el caso de la STEDH Sejdic' and Finci c. Bosnia Herzegovina de 22 de diciembre de 2009).

72 El actual parágrafo 10 señala: «Reiterates that strengthening the principle of subsidiarity is not intended to limit or weaken human rights protection, but to underline the responsibility of national authorities to guarantee the rights and freedoms set out in the Convention. Notes, in this regard, that the most effective means of dealing with human rights violations is at the national level, and that encouraging rights-holders and decision- makers at national level to take the lead in upholding Convention standards will increase ownership of and support for human rights «. Una aguda observación y seguimiento del Borrador de la Declaración de Copenhague y sus reacciones puede verse en A. Queralt JimÉnEZ, «El borrador de la Declaración de Copenhague sobre la efectividad del sistema europeo de garantía en el medio y largo plazo», Blog de la Revista Catalana de Derecho Público. Disponible en red en http://eapc-rcdp.blog. gencat.cat/tag/argelia-queralt-jimenez/

73 Ciertamente en el Informe del Grupo de Sabios señalado - y de acuerdo con la perfecta lógica con la que funciona la subsidiariedad cuando los estados parte están completamente implicados — hay una propuesta en orden a reenviar a los Estados para que determinen concretamente la cuantía de la compensación, caso de precisarse su necesidad por el TEDH. El Presidente del Comité que elaboró el informe, Gil Carlos Rodríguez Iglesias, expone que de esta manera se liberaría al Tribunal de esta tarea quedando en manos de los tribunales nacionales, que pueden atender mejor la complejidad eventual que puede requerir la fijación de indemnizaciones realmente reparatorias. Claro está que tal modelo sólo puede funcionar correctamente si en cada Estado miembro se establece un procedimiento apropiado, en el sentido, sobre todo, de que no arroje una carga insoportable sobre quienes han visto su derecho lesionado por el Estado que ahora tiene que compensarlo de su perdida. No es extraño que el Tribunal haya mostrado su más completa renuencia en las observaciones con las que se respondió al Informe del Comité de sabios. Cfr.: «La proposition tendant à transférer à l'ordre juridique national la tâche qui consiste à fixer le montant de la compensation requise pour offrir une satisfaction équitable à un requérant repose sur le souci de soulager la Cour d'une fonction qu'un organe national pourrait peut-être remplir plus efficacement. Toutefois, la Cour n'est pas convaincue que cette tâche serait, en règle générale, gérée plus efficacement par un organe judiciaire national. Elle rappelle que, vers la fin de l'année 2006, une division spécialisée chargée de la satisfaction équitable a été créée pour l'assister dans cet aspect de sa compétence. En définitive, l'intérêt de renvoyer systématiquement au niveau national cet élément de la procédure fondée sur la Convention ne semble pas avoir été démontré.

Pour les affaires où le traitement de l'article 41 est particulièrement complexe, la possibilité de renvoyer la question à une autorité nationale compétente, peut-être mieux placée qu'une juridiction internationale pour y répondre en tenant compte de la situation du marché local, pourrait être envisagée. Toutefois, il faudrait mettre en place des garanties institutionnelles et procédurales rigoureuses. Comme l'indiquent les Sages, il faudrait que l'autorité en question soit un organe judiciaire indépendant, qui fonctionne suivant une procédure équitable, efficace et facilement accessible. Il conviendrait de s'enquérir de l'opinion des instances judiciaires nationales compétentes sur cette proposition. La place d'un tel organe au sein du mécanisme de la Convention — par rapport à la Cour et au Comité des Ministres_- demande beaucoup de réflexion». Dictamen sobre el Informe del Comité de Sabios (en línea en http://www.echr.coe.int/Documents/2007_Wise_Person_Opinion_FRA.pdf). Cfr. las apreciaciones de G. C. 


\section{OBLIGATORIEDAD, EJECUTIVIDAD Y EFICACIA DE LAS SENTENCIAS DEL TRIBUNAL EUROPEO DE DERECHOS HUMANOS}

Continuando con el paradigma defendido, que tiene como aspectos claves la condición constitucional del Convenio y del TEDH, es obvio que la óptica debe centrarse ahora en el cumplimiento de las resoluciones del Tribunal de Estrasburgo. Evidentemente son aspectos tan interrelacionados que no podría mantenerse en modo alguno la cualidad constitucional que se ha defendido si las resoluciones no tuvieran un adecuado y generalizado cumplimiento. Sin poder acreditar alguna forma de eficacia, sin que quepa asegurar que una resolución del TEDH es capaz de alterar la realidad jurídica, tendríamos que dudar seriamente no solo del carácter constitucional del Convenio y del Tribunal sino de su misma cualidad normativa y jurisdiccional respectivamente.

Ello explica con toda claridad la relevancia que adquiere la capacidad modificativa que convenga atribuir a las resoluciones del Tribunal. Toda la credibilidad del sistema descansa sobre ellas. El Convenio reposa sobre el Tribunal y un tribunal no lo es si sus resoluciones no son consideradas como fuente del derecho.

Partiendo de aquí podríamos intentar esbozar las claves de un sistema que es ciertamente complejo ${ }^{74}$, analizando muy sintéticamente ${ }^{75}$ y solo respecto de las sentencias ${ }^{76}$, los siguientes aspectos: en primer lugar, la obligatoriedad del cumplimiento de las sentencias del Tribunal y las cuestiones relativas a la ejecutividad de las mismas; y en segundo término, las exigencias que pueden entrañar el cumplimiento de las sentencias del Tribunal de Estrasburgo.

Por lo que se refiere a la primera cuestión hay que resaltar que de las disposiciones incluidas en el CEDH y en el Reglamento de procedimiento del TEDH procede distinguir cuidadosamente entre obligatoriedad de las sentencias y ejecución de las mismas ${ }^{77}$. Efectivamente el artículo 46 (en la redacción dada por el Protocolo 14) se rotula «Fuerza obligatoria y ejecución de las sentencias» ${ }^{78}$. En él queda claro la obligación de acatamiento de las

RODRíGuez IGLESIAS, en «¿Qué hacer para asegurar la eficacia del sistema de control judicial del Convenio europeo de Derechos Humanos?», op. cit.

74 Tan complejo que el Informe del Consejo de Estado sobre la inserción del Derecho europeo en el ordenamiento español todavía podía decir a la altura de 2008: «La ejecución de las sentencias del Tribunal Europeo es un aspecto todavía mal conocido, pero que reviste una importancia capital». p. 293.

75 Solo se analizan aquellos aspectos que entendemos estrictamente necesarios para abordar las cuestiones fundamentales de este trabajo

76 Debemos de anotar, no obstante, la especial importancia que tienen las medidas cautelares y como son muy significativas del creciente protagonismo asumido por el TEDH con el solo amparo de lo establecido en el artículo 39 de su Reglamento de procedimiento. Por definición, una medida cautelar está vinculada al solo objetivo de frustrar una acción que podría dar lugar a una lesión grave e irreparable de uno de los derechos protegidos por el Convenio. Un sistema normativo con medidas cautelares es un sistema normativo que se toma a sí mismo muy en serio. Cfr. E. GARCÍA DE ENTERRÍA, La batalla por las medidas cautelares: derecho comunitario europeo y proceso contencioso administrativo español, Civitas, Madrid, 1995.

77 Tempranamente D. J. LiÑan Nogueras, «Los efectos de las sentencias del Tribunal Europeo de derechos Humanos en Derecho español», Revista española de derecho internacional, Vol. 37, n. ${ }^{\circ}$ 2, 1985, pp. 355-376.

78 «Artículo 46. Fuerza obligatoria y ejecución de las sentencias. 1. Las Altas Partes Contratantes se comprometen a acatar las sentencias definitivas del Tribunal en los litigios en que sean partes. 2. La sentencia definitiva del Tribunal será transmitida al Comité de Ministros, que velará por su ejecución. 3. Cuando el Comité de Ministros considere que la supervisión de la ejecución de una sentencia definitiva resulta obstaculizada por un 
sentencias que corresponde a las Partes contratantes en los litigios en que sean partes, señalándose al Comité de Ministros como órgano encargado de velar por su ejecución. Tal artículo podría abonar una interpretación, que enlaza también con la forma canónica de resolver la cuestión jurisprudencialmente ${ }^{79}$, según la cual la sentencia del Tribunal de Estrasburgo se limita a declarar la lesión y a llamar a los Estados miembros, en la lógica del principio de subsidiariedad, a ejecutarla. La sentencia sería, pues, meramente declarativa y el sistema previsto en el CEDH no contendría en puridad un modelo de ejecución de las resoluciones del Tribunal, entendiendo por tal según Garberi ${ }^{80}$, «el régimen jurídico que las normas establecen para el supuesto de que lo declarado en el fallo de una resolución judicial de condena resulte efectivamente incumplido (o no cumplido voluntariamente) por parte del sujeto a quien aquel pronunciamiento condene» ${ }^{81}$.

Así las cosas, esta aproximación dibuja un panorama sumamente precario e impreciso para el cumplimiento de las sentencias del TEDH y, en definitiva, para todo el modelo de derechos europeo que se apoya, como sabemos, en su dimensión jurisdiccional. En esta

problema de interpretación de dicha sentencia, podrá remitir el asunto al Tribunal con objeto de que éste se pronuncie sobre dicho problema de interpretación. La decisión de remisión al Tribunal se tomará por mayoría de dos tercios de los votos de los representantes que tengan derecho a formar parte del Comité. 4. Si el Comité considera que una Alta Parte Contratante se niega a acatar una sentencia definitiva sobre un asunto en que es parte, podrá, tras notificarlo formalmente a esa Parte y por decisión adoptada por mayoría de dos tercios de los votos de los representantes que tengan derecho a formar parte del Comité, remitir al Tribunal la cuestión de si esa Parte ha incumplido su obligación en virtud del párrafo 1. 5. Si el Tribunal concluye que se ha producido una violación del párrafo 1, remitirá el asunto al Comité de Ministros para que examine las medidas que sea preciso adoptar. En caso de que el Tribunal concluya que no se ha producido violación alguna del párrafo 1, remitirá el asunto al Comité de Ministros, que pondrá fin a su examen del asunto».

79 Cfr. TEDH Marckx c. Bélgica, 13 de junio de 1979: par. 58: «la sentencia del Tribunal es esencialmente declarativa y deja al Estado la elección de los medios a utilizar en su ordenamiento jurídico interno para adaptarse a lo que impone el artículo 53». También en el mismo sentido, el TJUE en el Dictamen 2/2013 sobre la eventual adhesión de la UE al CEDH: «El procedimiento ante el TEDH concluye bien con una decisión o una sentencia en las que el TEDH declara que la demanda es inadmisible o que no ha habido violación del CEDH, o bien con una sentencia que declara la violación del Convenio. Esta sentencia es declarativa y no afecta a la validez de los actos impugnados de la Parte Contratante». La aproximación canónica se completa en el par. 22 de la siguiente manera: «De conformidad con el artículo 46, apartado 1, del CEDH, las Partes Contratantes están obligadas a acatar las sentencias definitivas del TEDH en los litigios en que sean parte. En virtud de esta disposición, una Parte Contratante tiene la obligación, por un lado, de adoptar respecto del demandante todas las medidas individuales aplicables con arreglo a su Derecho interno para eliminar las consecuencias de la violación declarada en la sentencia del TEDH (restitutio in integrum). Si el Derecho interno de la Parte Contratante de que se trate sólo permite reparar de manera imperfecta las consecuencias de esa violación, el artículo 41 del Convenio dispone que el TEDH concederá «una satisfacción equitativa» al demandante. Por otro lado, una Parte Contratante está obligada a adoptar las medidas de carácter general, como una modificación de su ordenamiento jurídico interno, cambios jurisprudenciales u otro tipo de medidas, para prevenir nuevas violaciones análogas a las comprobadas por dicho Tribunal o poner término a las violaciones subsistentes en el citado ordenamiento»

80 J. Garberi Llobregat, «La ejecución en España de las sentencias del Tribunal Europeo de Derechos Humanos «, Diario La Ley , n. ${ }^{\circ} 8178,2013$, utilizando con precisión el utillaje doctrinal con el que la doctrina procesal actúa con referencia al derecho interno

81 Continúa señalando: «Para hacer efectivos los pronunciamientos judiciales de naturaleza condenatoria, pues, no basta con que el ordenamiento contenga normas que proclamen, con carácter general, la sujeción de poderes públicos y ciudadanos al imperio de la Ley (en España, art. 9.1 CE), o la abstracta obligación de cumplir lo dispuesto en las resoluciones judiciales (en España, art. $118 \mathrm{CE}$ ); de ser así, como veremos, el sistema de ejecución de sentencias previsto en el CEDH resultaría ser ciertamente impecable. Es necesario, además, que se prevea un procedimiento concreto para que, en caso de incumplimiento voluntario del fallo de una resolución judicial de condena, se pueda lograr el cumplimiento de dicho pronunciamiento de manera forzosa o coactiva» 
lectura se reduce la eficacia de las sentencias del Tribunal de Estrasburgo al establecimiento genérico de la obligatoriedad de aceptar el resultado condenatorio (esto es, reducida su eficacia al sujeto internacional que ha sido parte del litigio); la ejecución quedaría en manos del propio Estado, que gozaría a la hora de establecer los mecanismos concretos de una libertad difícilmente controlable; y un órgano político, no jurisdiccional, como el Comité de Ministros será quien, en la línea de los mecanismos tradicionales de carácter internacional, vele con lasitud por su cumplimiento. De este modo, podríamos hablar de una obligatoriedad ciertamente mermada; de una obligatoriedad con escasas dosis de eficacia en aquellos contextos en los que la ejecución no se considere una obligación firme por parte del ordenamiento estatal. Así concebido, sin un modelo de ejecución de sentencias, el Convenio quedaría desasistido en todos aquellos supuestos en los que el cumplimiento estatal de lo prescrito en el pronunciamiento jurisdiccional apareciera como muy gravoso. En definitiva, nos hallaríamos técnicamente ante un modelo internacional tradicional de declaración de derechos; un modelo de nuevo fallido por lo que se refiere a su garantía.

Cabe, sin embargo, proponer una visión diferente que se corresponde mucho mejor, entendemos, con la deriva actual del Tribunal y de sus sentencias. Efectivamente, si se observan con atención otras disposiciones del Convenio y del Reglamento de procedimiento así como los pronunciamientos del Juez de Estrasburgo, al hilo de la doctrina que profusamente se ha ocupado de la cuestión ${ }^{82}$, nos podemos encontrar con que la obligatoriedad viene progresivamente asumiendo una posición preeminente general. Según esta posición; 1) los Estados, desde luego, están obligados a observar los términos que se establezcan en el fallo que les condene, pero no son solo ellos los afectados por una sentencia condenatoria. Antes bien, se entiende que una sentencia en la que el Tribunal certifique la existencia de una lesión de un derecho del Convenio es una lectura actualizada del orden constitucional europeo y de ahí que haya de tener eficacia y ser de obligada observancia por el resto de los miembros del Consejo de Europa $^{83}$; 2) la obligatoriedad, separada conceptualmente de la ejecución — que solo es

82 Cfr. A. Queralt Jiménez, La interpretación de los derechos..., op. cit., pp. 71-137. Cfr. tb. A. DrzemcZEWSKI, «Quelques réflexions sur l'autorité de la chose interprétée par la Cour de Strasbourg», Rev. Fac. Direito UFMG, Belo Horizonte, n. ${ }^{\circ}$ 58, 2011, pp. 85-90. Claro que este autor es de los que vienen insistiendo desde hace mucho en la Convención como un «instrumento constitucional del orden público europeo». Véase, European Human Rights Convention in Domestic Law: a Comparative Study, Oxford, Clarendon Press, 1983, p. 19.

83 Cfr. como según se nos indica en el trabajo editado por D. AnAgnostou, «Untangling the domestic implementation of the European Court of Human Rights' judgments», op. cit, Suiza, lleva a cabo una verificación rutinaria de sus proyectos de ley con la convención pero también tiene en cuenta las sentencias del TEDH que se refieren a otros Estados (p.12). En esta dinámica que denomina preventiva incluye también a Alemania (p. 15). El caso de Suiza también es destacado por Anne Petters, en su muy interesante trabajo «El referéndum suizo sobre la prohibición de minaretes», Teoría y realidad constitucional, n. ${ }^{\circ}, 2010$, pp. 429-438 que destaca dos elementos importantes para este trabajo: 1) Que en la campaña a favor de la consagración constitucional de dicha prohibición se hicieron explícitos los problemas que en orden al respeto con el CEDH podía suponer; y 2) Que nos encontramos ante una posible infracción del CEDH por parte de un texto constitucional. Cierra su trabajo con la siguiente idea: «No está exento de riesgo buscar en instancias internacionales el remedio frente a decisiones democráticas (directas) de la mayoría que producen «daños sustanciales colaterales». Cualquier fallo del Tribunal Europeo de Derechos Humanos contrario a Suiza no hará sino alimentar en la ciudadanía el sentimiento y la sospecha frente a un «gobierno de jueces extranjero». En los últimos tiempos, la tensión entre la democracia directa y el respeto a los derechos humanos garantizados en sede internacional se pone de manifiesto. La tarea de reconciliar soberanía popular e imperio de la ley parece una historia interminable». Op. cit., p. 437. 
posible en rigor cuando la sentencia es condenatoria ${ }^{84}$ — es predicable también cuando la resolución introduce en su parte dispositiva algún elemento determinante de lo que el tribunal considera una solución jurídica compatible con el Convenio ${ }^{85}$. Así las cosas, el carácter declarativo de la sentencia que tiene como única referencia la condena singular de un estado palidecería frente a la obligatoriedad general de la doctrina del Tribunal que actualiza y hace un texto vivo del CEDH, el orden constitucional europeo; 3) de otro lado, la obligatoriedad de una resolución, normativa o jurisprudencial, está directamente anudada al grado de concreción de la misma. Desde este punto de vista se puede apreciar como el Tribunal ha procedido, como vamos a ver de inmediato, a cargar progresivamente de precisión sus previsiones, lo que conduce a una obvia reducción de la posibilidad del Estado de actualizarlas (uno de los elementos en los que se ampara la tesis del carácter meramente declarativo de la sentencia) ${ }^{86}$; 4) la obligatoriedad de la sentencia condenatoria recibe un refuerzo muy importante como consecuencia de la previsión específica del artículo $41 \mathrm{CEDH}^{87}$ que obliga al pago de una cantidad específica cuando se estime concurrente una violación y, de acuerdo con lo establecido en el artículo, el derecho interno «solo permita de manera imperfecta reparar las consecuencias de dicha violación». El artículo 41, es así una nueva muestra del repliegue de la teoría de la dimensión declarativa tout court de la sentencia del TEDH y una nueva concreción de la obligatoriedad que se predica y que cifra en la reparación tan perfecta, como sea posible, de la esfera lesionada (principio restitutio in integrum); y 5) la obligatoriedad también recibe un impulso por el hecho de que algunas de las nuevas dinámicas impulsadas por el TEDH, como por ejemplo, las Sentencias Piloto, hayan supuesto un reforzamiento de su posición jurídica y un desplazamiento del Comité de Ministros

84 En la doctrina procesalista esta cuestión aparece con toda claridad. Cfr., por ejemplo, J. VEGAS TORRES en A. De la Oliva Santos, I. Diez-Picazo Giménez, J. Vegas Torres Curso de Derecho procesal civil II. Parte especial, Ramón Areces, Madrid, 2014, p. 441: «una sentencia absolutoria, por definición, se limita a dejar las cosas como están, por lo que no hace falta ninguna transformación material de la realidad ni, por tanto, ninguna actividad jurisdiccional ejecutiva». La exclusiva vinculación de la ejecución con la sentencia condenatoria es otro argumento para optar por la obligatoriedad como principal criterio de comprensión de lo que significa la sentencia del TEDH.

85 Un ejemplo de ello es la Sentencia del Tribunal Europeo de Derechos Humanos Arribas Antón c. España, de 20 de enero de 2015 que, no siendo una sentencia condenatoria, hace una serie de precisiones que son completamente atendidas por el TC español desde la sentencia 9/2015. Como es sabido dicha sentencia resolvió un asunto que examinaba la compatibilidad con el CEDH del criterio de admisión previsto en el art. 5 de la LOTC que exige «la especial trascendencia constitucional» para admitir los recursos de amparo que se interpongan ante el Tribunal Constitucional. El Tribunal Europeo de Derechos Humanos determinó que el Tribunal Constitucional debía concretar el contenido de dicha cláusula y justificar su aplicación en los asuntos admitidos (par. 46).

86 Resulta interesante, a mi juicio, destacar que esta deriva era eventualmente tenida en cuenta en los debates en los que se discutía sobre los derechos a proteger en el Convenio o en los protocolos. Tal y como recuerda Ripol, algunos intervinientes se resistían a incorporar el derecho de propiedad porque ello exigiría una intervención especialmente «invasiva» por parte del TEDH sobre la esfera interna de los Estados. Cabe entender en este contexto la celebérrima sentencia que la que se inaugura la saga de las Piloto, Broniowski c. Polonia, de 22 de junio de 204. Las observaciones de Ripol en S. Ripol CARulla, «El sistema europeo de protección internacional de los derechos humanos y el derecho español», Estudio Preliminar a España en Estrasburgo. Tres décadas bajo la jurisdicción del Tribunal Europeo de Derechos Humanos (S. Ripol Carulla; J. M. Velázquez Gardeta; i. Pariente De Prada; J. I. Ugartemendia Eceizabarrena), Thomson, Pamplona, 2010, pp. 18-19.

87 «Si el Tribunal declara que ha habido violación del Convenio o de sus Protocolos y si el derecho interno de la Alta Parte Contratante sólo permite de manera imperfecta reparar las consecuencias de dicha violación, el Tribunal concederá a la parte perjudicada, si así procede, una satisfacción equitativa». 
como institución política internacional llamada por el CEDH a realizar la función de cierre del sistema ${ }^{88}$. Cabe apreciar en la evolución del CEDH un indiscutible movimiento hacia la juridificación, claramente expuesto en la progresiva marginación de las esferas predominantemente políticas en el proceso de garantía de los derechos. Un primer jalón de este movimiento es, desde luego, el Protocolo n. ${ }^{\circ} 11$, y en este proceso de transición seguimos.

En definitiva, creo que es posible afirmar que pese a una base jurídica no muy amplia, el activismo del Tribunal (en el que cabe integrar incluso su propio Reglamento, obra normativa enteramente suya ${ }^{89}$ ) ha logrado poner la obligatoriedad y la eficacia de sus sentencias como principio de general observancia, como concepto al que se concede una vis atractiva respecto del resto de los contructos procesales, de modo que a la cuestión de la ejecutividad de las mismas sea difícil y poco apropiado responder con un simple «sí» $\mathrm{o} «$ no ${ }^{90}$ y menos construir a partir de ahí la respuesta estatal ${ }^{91}$.

Ciertamente no se puede obviar que la misma sentencia del TEDH es incapaz de revertir aquellas actuaciones (generales o singulares; normativas, administrativas o jurisdiccionales) que hayan causado la concreta lesión del derecho que se declare quebrado. Pero solo porque su obligatoriedad se inserta en un modelo que funciona sobre la base de la subsidiariedad y se emplaza a los Estados miembros a que lo hagan. Por tanto las sentencias del TEDH no son, por ahora, ejecutivas pero el Estado tiene que hacerlas ejecutivas ${ }^{92}$. Así las cosas, si no lo hacen, o se advierten renuencias que puedan poner en una situación de vulnerabilidad al demandante que ha visto amparado su derecho o a eventuales víctimas, el TEDH advertirá que la subsidiariedad no cumple adecuadamente su función tuitiva e incluirá en el contenido de sus sentencias, además de la compensación indemnizatoria, específicas obligaciones, individuales o generales, de hacer $^{93}$. La ejecutividad es, pues, un expediente procesal útil, pero no

88 Cfr. Abrisketa Uriarte, op. cit., p. 79; y E. Lambert-Abdelgawad, «La Cour Européenne au secours du Comité des Ministres pour une meilleure exécution des arrêts "pilote» (en marge de l'arrêt Broniowski)», Revue Trimestrielle des Doits de l'Homme, vol. 61, 2005, pp. 203-224, p. 206.

89 Artículo 111 del Reglamento de Procedimiento.

90 A mi juicio, los conceptos procesales tradicionales de ejecutividad y eficacia resultan aproximaciones estáticas, concebidas exclusivamente dentro del paradigma estatal de referencia, que tienen muy serias dificultades para extrapolarse más allá de los tribunales nacionales, y que muestran una escasa receptividad frente a los paulatinos procesos de constitucionalización del orden jurídico europeo como el que se emprende en el seno del Consejo de Europa.

91 Creo que estos matices están presentes en el Auto de la Sala Segunda, de lo Penal, del Tribunal Supremo de 5 de noviembre de 2014 cuando señala en su FJ 2: «Sobre esta cuestión ya está superada la doctrina que sostenía que las SSTEDH solo tenían naturaleza declarativa y que por tanto no era posible anular la sentencia en la que se había apreciado la vulneración de los derechos reconocidos en el Convenio Europeo».

92 E. Carmona Cuenca señala en este sentido: «Lo ideal sería que las Sentencias del TEDH se ejecutasen «de oficio» y a la mayor brevedad posible». Final de su contribución en la Comisión de Venecia «Impacto y desafíos de la supervisión de cumplimiento de sentencias de los tribunales regionales de derechos humanos», intervención disponible en http://www.venice.coe.int/webforms/documents/?pdf=CDL-LA(2016)007-spa. Ya había señalado REQUEJO, «La articulación de las jurisdicciones internacional, constitucional y ordinaria en la defensa de los derechos fundamentales», op. cit., (nota a pie n. ${ }^{\circ} 41$ ) que el ordenamiento interno podría determinar la ejecutividad directa de las sentencias de Estrasburgo.

93 Una última reflexión merece ser meramente apuntada en este punto a la espera de aproximaciones más detenidas sobre este aspecto que, como hemos señalado, constituye uno de los más complejos de la cuestión que tratamos. Nuestro TC ha apoyado sus sentencias constitucionalmente en su publicación, la cosa juzgada y los efectos erga omnes (art. $164 \mathrm{CE}$ ). Ni siquiera en la LOTC ha habido una referencia a la ejecutividad de las sentencias hasta 
imprescindible, para que la sentencia del TEDH despliegue sus efectos. Lo relevante es la obligatoriedad. Y en ningún caso puede deducirse, reitero, de la ausencia explicita de ejecutividad en el CEDH un título para obstaculizar la fundamental obligación de todo Estado: la observancia inmediata de sus sentencias y de las exigencias generales y particulares que entrañan.

Desde este punto de vista hay que entender que el TEDH haya dejado la absoluta deferencia hacia los Estados en lo que se refiere a la ejecución de sus sentencias y se haya comportado como un Tribunal supranacional constitucional en materia de derechos fundamentales y, en este sentido, completamente atento a la gravedad de algunas lesiones sobre determinadas esferas (muy destacadamente la libertad personal ${ }^{94}$ ) para indicar con precisión en la sentencia medidas individuales o generales que habrán de ser adoptadas.

Considerando el segundo aspecto al que nos referíamos, las exigencias que pueden entrañar el cumplimiento de las sentencias del Tribunal de Estrasburgo, nos encontraremos con una confirmación de las tesis que aquí se mantienen. Si tradicionalmente se ha señalado que las sentencias del TEDH, sin carácter ejecutivo, imponían una mera obligación de resultado que dejaban al Estado condenado entera libertad para su logro, sería preciso apuntar que tanto el mencionado resultado como los medios para su consecución han sido progresivamente objeto de una depuración por parte del Tribunal ${ }^{95}$. En lo que se refiere a la primera cuestión — el resultado_ el Tribunal ha asumido con toda rotundidad su condición de tribunal constitucional sobre derechos fundamentales en un doble plano: subjetivo (estableciendo la restitutio in integrum) y objetivo (instando la corrección de los mecanismos internos generadores de nuevas lesiones por la misma causa ${ }^{96}$ ), lo que le ha llevado a erigir como líneas rectoras de su jurisprudencia una serie de principios:

1. Si la violación del derecho continúa produciéndose, ha de cesar ${ }^{97}$.

2. Cuando la lesión es consecuencia de una normativa interna que contradiga estructuralmente lo establecido en el Convenio, procede su reforma, independientemente

\footnotetext{
la Ley Orgánica 15/2015, de 16 de octubre, de reforma de la Ley Orgánica 2/1979, de 3 de octubre, del Tribunal Constitucional, para la ejecución de las resoluciones del Tribunal Constitucional como garantía del Estado de Derecho, que establece en el nuevo artículo 87.3: «Los Juzgados y Tribunales prestarán con carácter preferente y urgente al Tribunal Constitucional el auxilio jurisdiccional que éste solicite. A estos efectos, las sentencias y resoluciones del Tribunal Constitucional tendrán la consideración de títulos ejecutivos.» De esta secuencia (cuyo último episodio ha sido duramente criticado por razones técnicas por RuBIo LlORENTE, cfr. https://www.ahorasemanal.es/en-defensa-de-un-tribunal-amenazado) cabe deducir que la eficacia de las resoluciones de un tribunal no tiene porqué descansar siempre en la consideración como título ejecutivo de las sentencias que dicte.

94 Cfr. los casos Assanidze e Ilasco, que se mencionarán de inmediato.

95 A. Mowbray, «An Examination of the European Court of Human Rights' Indication of Remedial Measures», Human Rights Law Review, 2017, 17, 451-478.

$96 \mathrm{Al}$ aspecto objetivo debe sumarse el criterio de admisibilidad que el Protocolo 14 añade en el artículo 35.3.b) y que se centra en el daño relevante. En el informe explicativo de este criterio se menciona su conexión con el interés del particular o con el interés general. Cfr. A. Queralt, La interpretación de los derechos, op. cit., pp. 40 y ss.

97 Assanidze c. Georgia, de 8 de abril de 2004, que ordena la liberación del recurrente tan pronto como sea posible (pars. 202 y 203). Pocos meses después en un supuesto parecido la obligación de excarcelación se considera inmediata (Ilasco y otros c. Moldavia y Rusia de 8 de julio de 2004, par. 490). Como señala Mowbray («An Examination...», op. cit. p. 455) apoyándose en los correspondientes Informes anuales del Comité de Ministros,: « The above two judgments were major milestones in the Court's evolving role in providing respondent States with precise indications of the remedial measures they should take».
} 
del rango de esta normativa ${ }^{98}$, indicando incluso ocasionalmente ${ }^{99}$ la forma en que ha de ser modificada ${ }^{100}$.

3. No solo hay que pensar en la víctima en los términos establecidos en el CEDH - aspecto subjetivo - sino también en los potenciales sujetos que puedan sufrir una lesión a consecuencia de las mismas causas ${ }^{101}$.

4. Si la lesión se debe a una interpretación jurisprudencial es preciso arbitrar mecanismos para corregir esa interpretación de los jueces internos incompatible con el Convenio.

5. La Sentencia del TEDH concederá una «satisfacción equitativa» de acuerdo con el artículo 41 del TEDH cuando no se logre reparar íntegramente la lesión. En esta indemnización habrán de considerarse los diferentes tipos de daños causados, daños que pueden ser materiales y morales ${ }^{102} 103$.

98 Incluso si tiene un valor constitucional. Cfr. STEDH Sejdic' y Finci c. Bosnia Herzegovina de 22 de diciembre de 2009.

99 En otras ocasiones el TEDH deja en la penumbra de su parte dispositiva lo que procede hacer con la ley implicada en el caso (Cfr. STEDH Stern Taulat y Roura Capellera c. España de 13 de marzo de 2018 en cuyo parágrafo 35 se señala: «En matière d'offense envers un chef d'État, la Cour a déjà déclaré qu'une protection accrue par une loi spéciale en matière d'offense n'est, en principe, pas conforme à l'esprit de la Convention (Colombani et autres c.France, no 51279/99, §§ 66-69, CEDH 2002-V, Pakdemirli c. Turquie, no 35839/97, §§ 51-52, 22 février 2005, Artun et Güvener c.Turquie, no 75510/01, § 31, 26 juin 2007, et Otegi Mondragon c Espagne, no 2034/07, §§ 55-56, CEDH 2011). En effet, l'intérêt d'un Etat de protéger la réputation de son propre chef d'Etat ne peut justifier de conférer à ce dernier un privilège ou une protection spéciale vis-à-vis du droit d'informer et d'exprimer des opinions à son sujet (Otegi Mondragon précité § 55)». Incluso hay veces en que de manera harto discutible se anima a cuestionar la misma oportunidad de legislar en contextos que no entiende especialmente favorables. Cfr. SAS $c$. Francia de 1 de julio de 2014: «À ce titre, la Cour est très préoccupée par les indications fournies par certains des intervenants selon lesquelles des propos islamophobes ont marqué le débat qui a précédé l'adoption de la loi du 11 octobre 2010 (voir les observations du Centre des droits de l'homme de l'université de Gand et des organisations non gouvernementales Liberty et Open Society Justice Initiative, paragraphes 98, 100 et 104 ci-dessus). Il ne lui appartient certes pas de se prononcer sur l'opportunité de légiférer en la matière. Elle souligne toutefois qu'un État qui s'engage dans un processus législatif de ce type prend le risque de contribuer à la consolidation des stéréotypes qui affectent certaines catégories de personnes et d'encourager l'expression de l'intolérance alors qu'il se doit au contraire de promouvoir la tolérance (paragraphe 128 ci-dessus ; voir aussi le point de vue du Commissaire aux droits de l'homme du Conseil de l'Europe, paragraphe 37 ci-dessus)». Par. 149.

100 «To that end, the Court considers that section 39 of the Regulation on the Powers and Duties of the Gendarmerie should be amended to ensure that the relevant provisions are in compliance with Article 22 of Law no. 5607 on the Prevention of Smuggling [this provides that officers may only use firearms in self-defence when a suspect uses firearms» (Atiman c. Turquía de 23 de septiembre de 2014, par. 47)

101 «The respondent State must, within one year from the date on which the present judgment becomes final in accordance with Article $44 \S 2$ of the Convention, take all appropriate measures, preferably by means of a lex specialis ... to secure the establishment of a mechanism aimed at providing individual redress to all parents in a situation such as, or sufficiently similar to, the applicant's . ..» (STEDH Zorica Jovanovic c. Serbia de 26 de marzo de 2013. Par. 92)

102 En una nueva conexión con la visión constitucional, cada vez más acusada, podría observarse como los daños también han buscado conjurar nuevas lesiones a través de su consideración como punitivos. El daño, pues, dejaría de ser visto solo desde el punto de vista subjetivo para concebirlo al servicio de la salvaguardia de un sistema. Una defensa de los daños punitivos en la jurisprudencia de Estrasburgo puede verse en P. PINTo De AlburquerQUe y A. VAn AAKen, "Punitive Damages in Strasbourg», en University of St. Gallen Law School, Law and Economics Research Paper Series Working Paper No. 2016-05 Mayo 2016. Cfr. tb. C. Quesada AlCALÁ, planteando su concurrencia en el marco de las demandas interestatales: «Las víctimas encuentran su lugar ante el Tribunal Europeo de Derechos Humanos: Una «satisfacción equitativa» por la vulneración de sus derechos en las reclamaciones entre Estados (Chipre contra Turquía)», Revista de Derecho Comunitario Europeo, n. ${ }^{\circ} 49,2014$, esp. pp. 908 y ss.

103 Podríamos ver así como el sistema es una cadena de subsidiariedades que derivan de la absoluta prelación de la idea de derechos fundamentales. Esta cadena estaría compuesta por los siguientes escalones: 1) El Estado; 2) El 
A la vista de lo anterior, no es extraño que se haya podido hablar de la distorsión del carácter meramente declarativo de la STEDH ${ }^{104}$. Y es que seguramente haya llegado ya el momento de plantear una reforma del $\mathrm{CEDH}$ en la que toda esta nueva realidad se vea explícitamente reflejada en la norma en una forma que podría ser la siguiente: «El TEDH velará por el cumplimiento efectivo de sus resoluciones. Podrá disponer en la sentencia, o en la resolución, o en actos posteriores, las medidas de ejecución necesarias y, en su caso, resolver las incidencias de la ejecución». Nos acercaríamos así a las más audaces de las pretensiones pioneras que, tal y como nos recuerda Ripol Carulla, contaban con «crear una Carta de Derechos Humanos que garantice la libertad de pensamiento, de reunión y de expresión, así como el libre ejercicio de una oposición política; queremos un Tribunal de Justicia capaz de aplicar las sanciones necesarias para que se respete tal Carta». ${ }^{105}$

\section{EJECUTAR EN ESPAÑA LAS SENTENCIAS DEL TEDH}

Una vez alcanzada la conclusión de que el CEDH y TEDH tienen una inequívoca condición constitucional y que específicamente el TEDH es un tribunal que declara lesiones sobre derechos fundamentales con la obligatoriedad que esto supone, esta premisa debe proyectarse de manera clara sobre la cuestión de la ejecución de sus sentencias en el Reino de España.

En especial, ello nos lleva a un análisis de la cuestión que se aparta del que comienza poniendo como centro y eje de la investigación la problemática interna ${ }^{106}$ así como del que, de acuerdo con la línea anterior, parte exclusivamente de un análisis formal del tratado internacional utilizado para la ratificación del CEDH.

Este aspecto, en particular, requiere alguna observación adicional. Si efectivamente nos centramos en él tendremos como principal vía para deducir consecuencias jurídicas el artículo 94, que es el que sirvió para asumir el CEDH (un tratado, que, como es de sobra sabido, ni siquiera estaba explícitamente mencionado en la CE). Desde este punto de vista, el art. 94 se puede contraponer claramente al artículo 93, que establece la posibilidad de transferir competencias derivadas de la Constitución. Es posible así, cifrar la primera lectura de las relaciones entre CEDH y CE, en especial en lo que se refiere a la configuración de la potestad jurisdiccional, a partir del comprobable hecho de que la capacidad de juzgar y hacer ejecutar lo juzgado (una de las principales competencias derivadas de la constitución; una de las que dan sentido al estado constitucional — legislar, administrar, juzgar-) no había sido transferida, como sí lo fue en el caso del proceso de integración en las entonces llamadas Comunidades Europeas. Ello significaba cerrar completamente la cuestión de la ejecutividad de las SSTEDH: se reconocía un tribunal sin

CEDH; 3) Reparación integral; 4) Satisfacción equitativa. En la hipótesis de funcionamiento armónico el cuarto eslabón debiera ser el más infrecuente.

104 C. Montesinos Padilla, «El recurso de revisión como cauce de ejecución de las sentencias del Tribunal de Estrasburgo: pasado, presente y futuro», Eunomía. Revista en Cultura de la Legalidad, n. ${ }^{\circ}$. 10, 2016, pp. 98-113, p. 102.

105 Mensaje a los Europeos, iniciativa surgida en el marco del Congreso de Europa (La Haya 1948). Cfr. S. Ripol Carulla, «El sistema europeo de protección internacional de los derechos humanos y el derecho español», op. cit. p. 15.

106 Poner la problemática interna como eje supone poner tantos palos en las ruedas del sistema europeo de protección de derechos como Estados forman parte del Consejo de Europa. 
capacidad de hacer ejecutar sus resoluciones. De otro lado, el alcance limitado de la transferencia de soberanía también tenía importantes consecuencias en la medida en que el tratado podía ser utilizado como parámetro interpretativo pero no como parámetro de control de la constitucionalidad ${ }^{107}$. De esta forma se puede mantener un modelo formalmente dualista.

Sin embargo, esta visión nunca ha estado exenta de graves quiebras lógicas. La primera es, en mi opinión, la que se deriva del hecho de que suscribir el CEDH es asumir la capacidad del TEDH de juzgar; en concreto, supone que el Reino de España admite que un Tribunal en Estrasburgo pueda razonar jurídicamente y determinar en base a principios compartidos por la comunidad de tribunales de nuestro entorno si una persona ha visto conculcados los derechos garantizados en el Convenio por el Reino de España; implica admitir que el Tribunal es hábil para determinar si una ley ${ }^{108}$ (o incluso una Constitución ${ }^{109}$ ) al efectuar una restricción de unos de los derechos reconocidos en el Convenio ha actuado de acuerdo con los principios de necesidad y proporcionalidad, tal y como son entendidos en una sociedad democrática. Esto es, la potestad de juzgar sí se transfiere desde el momento en que se reconoce la competencia autónoma a un Tribunal para resolver conflictos jurídicos que versen sobre derechos fundamentales; ni más ni menos que sobre aquellos ámbitos que identifican la posición jurídica y corporeizan la dignidad humana en una comunidad política. Por tanto, más allá de la dualidad «transferencia o no de competencias derivadas de la Constitución» lo cierto es que una importante y operación constitucional comienza cuando se suscribe el Convenio (y ello no puede ser objetado sobre la base de que el 94 hubiera sido la vía elegida).

Ciertamente esta lectura de los artículos de la Constitución es una lectura alejada de formalismos y que tiene en cuenta específicamente los cambios en el contexto jurídico y la enorme progresión en los procesos de convergencia de derechos (pese a sus dificultades actuales motivadas por la recurrencia de crisis estructurales: económica, de seguridad, de proyecto europeo; constitucionales, en definitiva).

Estos cambios a los que me refiero son extraordinariamente importantes y la doctrina tiene que hacerse cargo de ellos para asumir lo que implica nuestra pertenencia al Consejo de Europa. En especial, es explicable la insistencia en el valor completamente resolutorio del artículo 94 en un momento en que CEDH y Comunidades Europeas eran dos polos de la construcción y de la recuperación de Europa, sí, pero completamente separados. En este momento la UE, como es sabido, ha reconocido el CEDH al máximo nivel. Lo hace de manera fundamental en la CDFUE (art. 52.3); establece la necesidad de que nos adhiramos a él en el art. 6.3 del TUE ${ }^{110}$ y el CEDH tiene una previsión específica sobre la adhesión de la UE en el art. 59.2. La proyección del CEDH y de la jurisprudencia del TEDH sobre el ordenamiento de la UE es sustancial, no accesoria. No siendo

107 Cfr., por todas, la fundamental STC 236/2007. FJ 5 que se recoge sin variaciones hasta hoy (cfr. STC $31 / 2018, \mathrm{FJ}^{\circ}$ )

108 CFR. STEDH Vermeire c. Bélgica, de 19 de noviembre de 1991.

109 Incluso, teóricamente, nuestra Constitución. Se pone premonitoriamente en esta tesitura R. Bustos, $L a$ constitución red, op. cit., p. 159.

110 Cfr. el Dictamen del TJUE 2/13. Sobre el mismo M. Azpitarte Sánchez, «Los derechos fundamentales de la Unión en busca de un nuevo equilibrio. Acerca del Dictamen 2/13 del Tribunal de Justicia». Revista Española de Derecho Constitucional, núm. 104, 2015, págs. 243-268. 
realidades netamente separadas en la actualidad resulta poco operativo como argumento el que sigue distinguiendo entre los procedimientos originariamente adoptados para contraer obligaciones con otros sujetos de derecho internacional.

De otro lado, habría que considerar lo que supone el artículo $10.2 \mathrm{CE}^{111}$, cuya contribución al régimen jurídico de la ejecución de sus sentencias es, sin embargo, bien escasa en la medida en que se limita a favorecer de forma inespecífica y respecto de cualquier tratado internacional (y otros textos que no lo son, como la DUDH) un contexto deferente hacia la convergencia de derechos.

Sin duda su importancia ha de ser reconocida y valorada sobre todo en la medida en que el TC se ha servido de él para contemplar la interpretación de los órganos de garantía establecidos en los textos ${ }^{112}$, atribuyéndoles la capacidad, incluso, de conmover el entendimiento que el propio TC haga de los derechos fundamentales ${ }^{113}$. Sin embargo, es preciso insistir en que lo que el TC señala es que los derechos fundamentales son solo los de la Constitución y que los tratados internacionales y la doctrina de sus órganos de garantía constituirán parámetros interpretativos ( privilegiados», si se quiere ${ }^{114}$ ), «valiosos criterios hermeneúticos» ${ }^{115}$, que podrán concurrir junto con otros en la determinación del contenido de la norma. En el 10.2, pues, hay una serie de magnitudes de las que hay que partir:

1. La prioridad del derecho fundamental radicado, en exclusiva, en la Constitución;

2. Una realidad normativa $-\mathrm{y}$ ocasionalmente jurisprudencial- estraestatal de diferente densidad; $y$

3. Una obligación de interpretar la primera conforme a la segunda. Es explicable así, que de esa combinatoria resulten diferentes resultados — favorables en algunos casos, desfavorables en otros- en orden a la garantía de los derechos reconocidos en el tratado correspondiente ${ }^{116}$. No es ese objetivo que el artículo 10.2 tiene.

111 A. SaIz Arnárz, La apertura constitucional al derecho internacional y europeo de los derechos humanos: el artículo 10.2 de la Constitución española, Consejo General del Poder Judicial, Madrid, 1999. A. Schillacci, Diritti fondamentali e parametro di giudizio. Per una storia concettuale delle relazioni tra ordinamenti, Jovene, Nápoles, 2012.

112 STC 116/2006. «las normas relativas a los derechos fundamentales y libertades públicas contenidas en la Constitución deben interpretarse de conformidad con los tratados y acuerdos internacionales sobre las mismas materias ratificados por España (art. 10.2 CE); interpretación que no puede prescindir de la que, a su vez, llevan a cabo los órganos de garantía establecidos por esos mismos tratados y acuerdos internacionales (STC 81/1989 de 8 de mayo, FJ 2)». En el mismo sentido cfr. STC 198/2012 Y 13/2017. El artículo 10.2 resulta fundamental para afirmar el efecto de cosa interpretada de las STEDH.

113 STC 155/2009: Concurre la especial trascendencia constitucional necesaria para admitir un Recurso de Amparo cuando el Recurso «dé ocasión al Tribunal Constitucional para aclarar o cambiar su doctrina, como consecuencia de (...)un cambio en la doctrina de los órganos de garantía encargados de la interpretación de los tratados y acuerdos internacionales a los que se refiere el art. 10.2 CE». FJ 2.

114 STC 64/1991.

115 STC $13 / 2017$, siguiendo la STC 61/2013.

116 Entender que el derecho a la inviolabilidad de domicilio debe incluir la protección contra graves y persistentes episodios de contaminación acústica (Casos López Ostra y Moreno Gómez, STC 150/2011, con un muy significativo voto particular al respecto del Magistrado Manuel Aragón Reyes) mientras que se descarta la reagrupación familiar (STEDH caso Johansen, de 27 de junio de 1996, par. 52) como parte del concepto de intimidad domiciliaria. (STC 186/2013). 
Las conexiones entre interpretación conforme y ejecución de las sentencias del TEDH no siendo irrelevantes (pues, en la medida en que sirvan para aproximar los estándares, hacen más difíciles las lesiones de los derechos contenidos en los tratados; y cuando éstas quedan acreditadas dificultan su reiteración) son, pues, muy mediatas.

En definitiva, la sola llamada a la interpretación de los derechos conforme a los tratados internacionales sería en buena medida vana ${ }^{117}$ si: a) en los tratados internacionales concretamente ratificados no se contuvieran referencias específicas que determinaran la necesidad de observar los Tratados y las sentencias en las que al Estado se condene (lo que ya hemos tenido la ocasión de comprobar en los apartados anteriores); y b) el texto constitucional no permitiera integrar una obligación cierta e indiscutible de dar cumplimiento a las sentencias correspondientes.

Este último aspecto debe ser el que centre nuestra atención ahora. Al respecto me interesa señalar que la obligación constitucional de proveer la ejecución de las sentencias del TEDH tiene dos fuentes: en primer lugar, el artículo 96.1 que, como es sabido, establece en su primer inciso: «Los tratados internacionales válidamente celebrados, una vez publicados oficialmente en España, formarán parte del ordenamiento interno» ${ }^{118}$. Así pues, cuando el Estado suscribe un tratado internacional se compromete a cumplir con las obligaciones y exigencias que este tratado tiene. Si el tratado es sobre derechos humanos y cuenta con un tribunal que vela por su garantía asume que sus sentencias desplieguen internamente los efectos que cualquiera que determine la lesión de un derecho debe tener.

No queda más remedio que admitir, sin embargo, como hecho relevante, que este artículo se refiere a cualquier tratado internacional lo que supone no contextualizar adecuadamente lo que representa en términos constitucionales la no observancia de una sentencia que determine la lesión de uno de los derechos contenidos en el Convenio Europeo de Derechos Humanos, ni para el Estado ni para el justiciable. Esto es, un tratado genérico podrá verse desplazado en su aplicación por otra fuente del derecho interno cuando se den ciertas circunstancias ${ }^{119}$; incluso podría ser declarado inconstitucional (artículo 27 LOTC) ${ }^{120}$ sin estimar en modo alguno el objeto de juicio como parte del parámetro. Ninguna de las dos eventualidades cabe cuando se piensa en el CEDH. Si el 96 no las impide y el CEDH no las admite, no pisamos terreno lo suficientemente firme como para deducir de este artículo una improrrogable obligación de ejecución de lo establecido en los Tratados. En definitiva, la genérica observancia del pacta sunt servanda de los Tratados internacionales y el artículo 96 de la CE no clausura toda forma de oposición a una sentencia condenatoria del Estado por el TEDH. ¡Qué se asuma la responsabilidad internacional!,

117 De esta vanidad es exponente la falta de observancia de algunos derechos reconocidos, por ejemplo, en el Pacto Internacional de Derechos Económicos, Sociales y Culturales. Así se ha destacado en el último informe periódico relativo a España aprobado el 25 de abril de 2018 por el Comité de Derechos Económicos, Sociales y Culturales.

118 Cfr. el reciente desarrollo en la Ley 25/2014, de 27 de noviembre, de Tratados y otros Acuerdos Internacionales.

119 Un caso bastante ilustrativo de este aspecto es la peripecia judicial en el caso Couso. Mientras la AN entendió en el Auto del Juzgado Central de Instruccion uno de 17 de marzo de 2014 que debía inaplicar la reforma de la LOPJ que limitaba los supuestos de jurisdicción universal, por ser contraria a la IV Convención de Ginebra , posteriormente archivó el caso en el Auto que dictó con fecha de 9 de junio de 2015, una vez considerada la lectura de la compatibilidad de la reforma de la LOPJ con la citada Convención que realizó el TS en la Sentencia de la Sala Segunda del TS de 6 de mayo de 2015 (caso Genocidio Tibet)

120 STC 38/2007, FJ 3. 
dirán los que entiendan que el Tratado y el Tribunal de Estrasburgo exigen más de lo que el Estado puede conceder. Una lógica, pues, estrictamente dualista no permite alcanzar la primera lógica interna que cualquier tratado — no de reconocimiento sino de garantía de derechos ${ }^{121}$ — persigue: que sea observada la sentencia condenatoria.

La segunda fuente constitucional, en mi opinión mas contundente y precisa, que exige el establecimiento de un sistema interno de ejecución de sentencias del TEDH es el derecho a la tutela judicial efectiva. Aquí nos situamos en la perspectiva de los derechos, no de las fuentes, como en el caso anterior, y emplazamos a la persona como centro capaz de exigir obligaciones al Estado. No es ya la comunidad internacional la que impele a cumplir con el tratado; es la persona cuyos derechos se garantizan la que obliga al Estado, como responsable primero, a que ejecute la sentencia. Ello implica asumir conjuntamente una serie de elementos:

1. La persona es titular de los derechos fundamentales.

2. La persona tiene derecho a la tutela judicial efectiva de los jueces y tribunales (artículos 24 CE; 6 y 13 CEDH).

3. El TEDH es un tribunal que trata sobre la esencia de la materia constitucional: los derechos fundamentales.

4. La tutela judicial efectiva integra el derecho a que el juez aplique la ley ${ }^{122}$ y el derecho a la ejecución de la sentencia recaída ${ }^{123}$.

121 De nuevo A. SaIz Arnárz, «El Convenio de Roma, el Tribunal Europeo de Derechos Humanos y la cultura común de los Derechos fundamentales en Europa», op. cit.

122 En este sentido resulta meridianamente claro el razonamiento de la Sala de lo Penal de la Audiencia Nacional (Pleno) de 22 de octubre de 2013: » El Convenio Europeo integra nuestro ordenamiento juridico, según el art. 96.1 de la Constitucion (Ce, en adelante), y las normas relativas a derechos fundamentales y libertades públicas deben interpretarse de conformidad con los Tratados internacionales (art. 10.2 Ce); el Tribunal Europeo es el Grgano cualificado de interpretaci6n del Convenio y sus decisiones son obligatorias y vinculantes para todo Estado parte. Los jueces y los tribunales están sometidos con exclusividad ala ley, úinica fuente de legitimidad de su actuaci6n (art. 117 CE). Aquí, sujeción a la ley significa vinculación al Convenio y a las decisiones y doctrina de su 6rgano de garantía jurisdiccional.» (FJ 3). Un seguimiento del mismo puede encontrarse en A. QuerALt JiMÉNEZ, «Crónica de una ejecución anunciada: la efectividad en España de la STEDH Del Río Prada en España», en M. Pérez Manzano, J.A. Lascuraín Sánchez (dirs.), La tutela multinivel del principio de legalidad penal, op. cit. pp. 349-375; C. RuIz MIGUEL, «La STEDH sobre la doctrina Parot y el problema de la ejecución de las sentencias del TEDH», op. cit. pp. 377-408. A. Figueruelo Burrieza «Diálogo entre Tribunales: la Sentencia del Tribunal Europeo de Derechos Humanos de 21-X-2013 (Caso Sra. del Río contra Reino de España), en M.A. García Herrera, J. Asensi Sabater, F. Balaguer Callejón (coord..) Constitucionalismo crítico: Liber amicorum Carlos de Cabo Martín, Vol. 1, 2016, , pp. 853-874

123 La configuración de esta relación se aprecia con toda claridad en sentencias como la 73/2010 en cuyo fundamento jurídico 10 constan las siguientes palabras: «el derecho a la tutela judicial en la que se integra el derecho a la ejecución «se califica por la nota de efectividad» en nuestra Constitución (STC 1/1981, de 26 de enero, FJ 1). Por lo que hemos declarado que sólo cuando se da cumplimiento a las resoluciones judiciales firmes «el derecho al proceso se hace real y efectivo ya que, si fuera de otro modo, el derecho no pasaría de ser una entidad ilusoria» (STC 61/1984, de 16 de mayo, FJ 1), al igual que las decisiones judiciales «no serían otra cosa que meras declaraciones de intenciones sin alcance práctico ni efectividad alguna» (STC 107/1992, de 1 de julio, con cita de las SSTC 167/1987, de 28 de octubre, y 92/1988, de 23 de mayo). De otro lado, también se ha declarado que el cumplimiento de lo acordado por los Jueces y Tribunales en el ejercicio de su función jurisdiccional constituye una «exigencia objetiva del sistema jurídico» y «una de las más importantes garantías para el funcionamiento y desarrollo del Estado de Derecho» (STC 15/1986, de 31 de enero, FJ 3), pues implica, entre otras manifestaciones, «la vinculación de todos los sujetos al ordenamiento jurídico y a las decisiones que adoptan los órganos judiciales, no sólo juzgando sino también haciendo ejecutar lo juzgado» (STC 107/1992, FJ 2, con cita de las SSTC 67/1984, de 7 de junio, y 92/1988, de 23 de mayo).» 
De acuerdo con lo anterior, la tutela judicial efectiva del artículo 24 se vería lesionada en todos aquellos casos en los que una sentencia no fuera ejecutada o solo fuera imperfectamente ejecutada ${ }^{124}$. En el ordenamiento constitucional interno esta vinculación entre juzgar y hacer ejecutar lo juzgado se presenta de forma diáfana en el artículo 117 y el juez es el único referente interno en esta cadena para asegurar su cumplimiento. Como esta solución es posible se instaura como mejor garantía. Pero el hecho de que el $\mathrm{CEDH}$ establezca obligadamente una escisión orgánica entre las dos funciones no permite desatender la segunda porque daríamos lugar simultáneamente a una lesión del artículo 6 del Convenio y del artículo 24 CE.

En definitiva, salvo que no consideremos órgano judicial al TEDH ${ }^{125}$, es constitucionalmente imperativo establecer un sistema que haga posible la ejecución de sus sentencias por constituir parte del derecho que el titular del derecho a la tutela judicial efectiva tiene ${ }^{126}$.

España, pues, se ha visto confrontada a esta exigencia: establecer un sistema de ejecución de las sentencias condenatorias del TEDH no solo era una obligación desde el punto de vista del $\mathrm{CEDH}^{127}$ sino también un imperativo constitucional.

No existe, por tanto, y respecto de ninguna materia ${ }^{128}$, la posibilidad de no ejecutar una sentencia del TEDH, y si la carencia de un sistema específico para la ejecución pretende alegarse como excusa para su no cumplimiento, se debe proceder a establecer uno.

En la frase anterior se encuentra un panorama indicativo de la situación de la ejecución de las sentencias en España. De un lado, hay que partir de que nuestro país se ha comportado como buen cumplidor de lo establecido en el Convenio ${ }^{129}$. No obstante, no ha contado, como es sabido, hasta muy recientemente con un sistema específico para la ejecución de las

124 El planteamiento general y canónico sobre la tutela judicial y la ejecución de sentencias está contenido con precisión en la Exposición de Motivos de la Ley de la Jurisdicción contencioso-administrativa: «El punto de partida reside en la imperiosa obligación de cumplir las resoluciones judiciales y colaborar en la ejecución de lo resuelto, que la Constitución prescribe, y en la potestad de los órganos judiciales de hacer ejecutar lo juzgado, que la propia Constitución les atribuye. Prescripciones que entroncan directamente con el derecho a la tutela judicial efectiva, ya que, como viene señalando la jurisprudencia, ese derecho no se satisface mediante una justicia meramente teórica, sino que conlleva el derecho a la ejecución puntual de lo fallado en sus propios términos. La negativa, expresa o implícita, a cumplir una resolución judicial constituye un atentado a la Constitución frente al que no caben excusas.»

125 Podríamos traer a colación aquí la Propuesta de reforma de Ley Orgánica del Poder Judicial, elaborada por la comisión institucional creada por Acuerdo de Consejo de Ministros, de 2 de marzo de 2012, para la elaboración de una propuesta de Texto articulado de Ley Orgánica del Poder Judicial y de Ley de demarcación y planta judicial, que incorporaba un artículo 5 con el siguiente tenor: «1. Lo dispuesto en los artículos anteriores no será óbice para el reconocimiento de la jurisdicción de aquellos Tribunales supranacionales e internacionales instituidos por tratados internacionales en que España sea parte».

126 Este es el planteamiento de la STC en el caso Bultó. Señala E. Carmona: «la imposibilidad de acceso a la revisión de una resolución judicial firme, necesaria para el cumplimiento de una sentencia del TEDH, constituía una vulneración del derecho a la tutela judicial efectiva reconocido en el art. 24 de la Constitución». Disponible en http://www.venice.coe.int/webforms/documents/?pdf=CDL-LA(2016)007-spa

127 En rigor el CEDH exige su ejecución no exactamente un sistema para su ejecución, aunque el Consejo de Ministros ha aprobado resoluciones en este sentido. Cfr. por ejemplo, la Recomendación (2000)2, del Comité de Ministros. Montesinos Padilla da cuenta de diferentes Resoluciones en las que el Comité de Ministros expresa su preocupación ante la incomparecencia de un procedimiento específico en España. Cfr. «El recurso de revisión... », op. cit., p. 110 , nota a pie n. ${ }^{\circ} 15$.

128 Hay previstas soluciones de escape en determinados momentos que deberíamos considerar excepcionales. Cfr. el artículo $15 \mathrm{CEDH}$.

129 https://www.echr.coe.int/Documents/Overview_19592017_FRA.pdf 
sentencias condenatorias. Ello ha acarreado una suerte desigual a las diferentes obligaciones que de ellas se derivaban: solo las pecuniarias (satisfacción equitativa) se han hecho frente sin ningún problema, en tanto que han presentado muchos más problemas las exigencias derivadas de la reapertura de los procesos judiciales y las que venían a comprometer al Estado en reformas normativas ${ }^{130}$. Las últimas se han hecho de rogar durante bastantes años ${ }^{131}$.

Pero sin duda han sido las que exigían la revisión de los pronunciamientos jurisdiccionales las que han atribulado más al sistema interno. En este sentido hay que aludir, por su destacada significación a la STC 245/1991 (caso Bultó) que llega a plantearse al recurso de amparo como instrumento hábil para declarar la nulidad de aquellas sentencias firmes que hubieran sido las causantes de la lesión de los derechos protegidos por el Convenio. Como es sabido, esta cuestión ha representado un complejo dilema incluso en el seno del TC. Y es que cuando en dicha sentencia nuestro más alto tribunal razona de esta forma se está colocando a sí mismo en una posición muy difícil, en una situación que es insostenible según los parámetros clásicos porque tal actuación vendría a suponer que el TC constituiría en esos casos un mero ejecutor de la doctrina del $\mathrm{TEDH}^{132}$ (algo que no encontraba un encaje claro ni en la Constitución ni, desde luego, en la LOTC) ${ }^{133}$. Las consecuencias de tal admisión son tan importantes que no es extraño que el TC se haya mantenido decididamente alejado de esta doctrina ${ }^{134}$.

130 La modificación que de la LOTC debía deducirse tras la STEDH Ruiz Mateos c. España de 23 de junio de 1993 se hizo esperar hasta la LO 6/2007 (en cuya Exposición de Motivos se hace específica mención de la STEDH). En lo relativo a las deficiencias en la regulación del secreto de las comunicaciones que habían sido observadas reiteradamente desde la STEDH Valenzuela Contreras c. España de 30 de julio de 1998, estas solo han sido colmadas con la reciente modificación de la Ley de Enjuiciamiento Criminal (Ley Orgánica 13/2015, de 5 de octubre, de modificación de la Ley de Enjuiciamiento Criminal para el fortalecimiento de las garantías procesales y la regulación de las medidas de investigación tecnológica.)

131 La laxitud con la que ha actuado el Consejo de Ministros en sus resoluciones sobre el cumplimiento de las SSTEDH es oportunamente destacada por D. D. ANAGNOSTOU, «Untangling the domestic implementation of the European Court of Human Rights' judgments», op. cit, p. 7.

132 Todavía hoy nuestro TC está bien lejos de asumir una posición que él mismo no considere lo suficientemente fuerte. Cfr. en este sentido la STC 26/2014 recaída ante el caso Melloni tal y como lo advierten los votos particulares (en particular el de la magistrada Adela Asua Batarrita).

133 El Voto Particular de Gimeno Sendra establece: «(...) lo cierto es que la Sentencia TEDH de 6 de diciembre de 1988 se ejecuta por este Tribunal en sus propios términos, viniendo a convertir al Tribunal de Estrasburgo en una «supercasación constitucional» y a este Tribunal constitucional en un órgano ejecutor de las Sentencias de aqeul, lo que es mi opinión es constitucional y jurídicamente inadmisible». Años después señalaría el TC en el Auto 119/2010: «Sin necesidad de extendernos en consideraciones acerca de cuáles debieran ser el cauce procesal y el alcance de una hipotética ejecución de lo resuelto por el Tribunal Europeo de Derechos Humanos, parece claro que este Tribunal no puede acometerla. En efecto, como ha recordado la STC 116/2006, de 24 de abril, «la discusión sobre la ejecución interna de las resoluciones de los organismos internacionales competentes en materia de derechos humanos -y, en concreto, sobre las Sentencias del Tribunal Europeo de Derechos Humanos y los Dictámenes del Comité de Naciones Unidas- es una cuestión ajena a la competencia y jurisdicción de este Tribunal» (FJ 4), y ello aun cuando la violación del CEDH se haya producido específicamente en el seno de un proceso constitucional, pues el Tribunal Constitucional, sujeto únicamente a la CE y a la LOTC (art. 1.1 LOTC), no puede revocar sus providencias de inadmisión de recursos de amparo más que en virtud de las previsiones explícitas y específicas existentes en la LOTC sobre los medios impugnatorios frente a sus resoluciones, sin que sea posible - como se ha dicho en el reciente ATC 46/2010, de 14 de abril— entrar a debatir siquiera la aplicación de reglas extrañas a la misma». Es llamativo, a juicio de este observador, que el Tribunal se decida a traer a colación un párrafo de una jurisprudencia en la que las Sentencias del Tribunal Europeo de Derechos Humanos y los Dictámenes del Comité de Naciones Unidas se presentan indiferenciadamente.

$134 \mathrm{El}$ propio TC la ha considerado propia de una situación de excepcionalidad dadas las circunstancias que concurrían en el caso (cfr. ATC 119/2010. FJ 3). Sin embargo me parece necesario destacar como ha quedado como 
Por ello ha constituido desde hace mucho tiempo un lugar común reivindicar un procedimiento específico ${ }^{135}$. Y es explicable que este procedimiento se haya establecido, con una contigüidad temporal nada casual, tras las resoluciones judiciales dictadas por la Audiencia Nacional determinando la excarcelación de las personas afectadas por la doctrina del TEDH (Gran Sala) en la Sentencia Del Río Prada de 21 de octubre de $2013^{136}$. Este caso ha de verse como paradigmático de las dificultades que todos los Estados tienen para afrontar sentencias condenatorias cuando recaen sobre aspectos a los que la opinión pública nacional es especialmente sensible ${ }^{137}$. Materias como la inmigración, el trato dado a las minorías, las relaciones entre el Estado y las confesiones religiosas, la forma de ordenar los procesos políticos y el acceso al poder, las respuestas a los desafíos extremos al orden constitucional, como los que representan el terrorismo, entre otras, son un campo de minas. Un ordenamiento constitucional interno que se vea corregido en cualquiera de estos aspectos ${ }^{138}$ podrá tener problemas para neutralizar los argumentos de quienes llegan a cuestionar la legitimidad de una sentencia de Estrasburgo para condenar al Estado ${ }^{139}$.

un leading case en el que se ha apoyado la doctrina jurisprudencial más comprometida en la atribución de efectos a las sentencias condenatorias del TEDH. Cfr., por ejemplo, como sirve de partida de apoyo a la Sala de lo Penal del Tribunal Supremo en el Auto de 5 de noviembre de 2014, primero de los autos en los que aplica la vía del recurso de revisión para la ejecución de las sentencias del Tribunal Europeo de Derechos Humanos.

135 Por ejemplo, en el Informe del Consejo de Estado sobre la inserción del Derecho Europeo en el ordenamiento español, instando a que sea el Tribunal Supremo el que tenga la competencia para decidir sobre la reapertura de los procesos cuestionados.

136 El hecho de que hayan sido los órganos jurisdiccionales los que hayan establecido el procedimiento (Acuerdo del pleno de la Sala de lo Penal del Tribunal Supremo de 21 de octubre de 2014) antes de que el legislador arbitrara la solución presenta, sin duda, importantes problemas (cfr. C. RUIZ MigUEL, «La STEDH sobre la doctrina Parot y el problema de la ejecución de las sentencias del TEDH», op. cit., p. 405). La intervención judicial puede, no obstante, ser considerada como una lectura directa del ordenamiento constitucional. Una contumaz pasividad del legislador ante demandas jurídicas imperiosas lleva quienes tienen que administrar justicia a actuar con lo que de otro modo cabría calificar de intervencionismo desmedido.

137 Sobre esta cuestión es relevante el trabajo editado por Dia Dianagnostou, The European Court of Human Rights. Implementing Strasbourg's Judgements on Domestic Policy, op. cit. Es interesante esta obra en la medida en que muestra cómo en algunas ocasiones los Estados son más o menos reticentes a cumplir con las sentencias condenatoria en function de su contenido. Por ejemplo, en el caso de Reino Unido (según se refiere en el capítulo elaborado por K. Brayson y G. SWAIN, «The European Court of Human Rights and minorities in the United Kingdom: catalyst for change or hollow rhetoric?», pp. 188-211) se destaca como no se objeta el cumplimiento de las que han determinado la violación de los derechos de los homosexuales o trangénero pero sí se presentan más dificultades para aceptar las implicaciones de aquellas sentencias que mantienen que los gitanos han sido objeto de violencia policial. La autora mantiene que eso se debe a la diferencia de apoyo social que reciben las diferentes minorías así como al hecho de que las cuestiones relativas a la actuación de la policía están vinculadas a la seguridad nacional y al orden público. Cfr. p. 18

138 Y es que, no se olvide, algunos de ellos, como, por ejemplo, la seguridad nacional, aparecen como reductos estatales incluso frente al proceso de integración europea (cfr. art. 4.2 TUE)

139 Apoyos muy señeros a estas posiciones no faltan tampoco entre la doctrina foránea. Cfr. «This means first and foremost that the States must implement the ECHR in their domestic legal orders and follow the case law of the Court; but States must also do more than that. States may and must, depending on the circumstances, deviate from the case law of the Court and independently strike a fair balance between opposing forces and provide their own answers to pertinent human rights issues. States need to provide answers that have "higher legitimacy than those given by the Court». J. Christoffersen «Individual and Constitutional Justice: Can the Power Balance of Adjudication be Reversed?», en J. CHristoffersen y M. RASK MADSEN The European Court of Human Rights between Law and Politics, op. cit., p. 181. Resulta interesante destacar el papel de este autor en la reciente Declaración de Copenhague cuyo Draft ya hemos tenido la ocasión de criticar en la sede oportuna (Cfr. el post de Helga Molbæk-Steensig, «Something Rotten in the State of Denmark?», disponible en https://verfassungsblog. 
Puede entenderse así que, la ley 7/2015 se hiciera finalmente imperiosa tras la corrección por el TEDH de la doctrina Parot y, cuando al socaire de la inexistencia de mecanismo específico para ejecutar una sentencia que afectaba a una cuestión tan sensible como las condenas por terrorismo, comenzaban a esgrimirse con creciente fuerza argumentos como la subsidiariedad del mecanismo previsto por el Convenio, o la sujeción exclusiva del juez a la ley interna.

En definitiva, la inexistencia de un instrumento de desarrollo concreto dio alas a la tentación de inobservancia, peligro que el Gobierno quiso conjurar planteando la iniciativa que concluyó con la aprobación de la ley orgánica $7 / 2015^{140}$. En ella se habilita el recurso de revisión en los cuatro órdenes jurisdiccionales ${ }^{141}$. Ciertamente esta

de/author/helga-molbaek-steensig/) En el fondo esto no es otra cosa que un seguimiento de la doctrina del TCA Görgülü (sobre la misma C. FERCOT, «Les effets des arrêts de la Cour européenne des droits de l'Homme en droit allemand. Analyse de la jurisprudence récente de la Cour de Karlsruhe et regards sur le droit français», Revue française de droit constitutionnel, 2007, vol. 71, pp. 639-665; en la doctrina española repara en ella M. GonZÁLEZ PASCUAL, El Tribunal Constitucional alemán en la construcción del espacio europeo de los derechos, Madrid, Civitas/Thomson Reuters, 2010) y un intento de volver a poner la autonomía de los Estados un punto más allá del mero margen de maniobra atribuido a los mismos para elegir el medio de cumplir una sentencia. Los Estados son los que deben dar la respuesta pertinente cuando ellos estimen que el caso lo requiere. Como es evidente esta doctrina pone a la sentencia condenatoria a los pies de los caballos en el caso de que afecte a una materia sensible, haciendo desaparecer la función tuitiva que representa una jurisdicción supranacional de los derechos humanos justo en aquellos aspectos que más se necesitan. Resulta indiscutible también que con esta visión las disputas dejan de estar definitivamente resueltas y propician una serie de enfrentamientos políticos dentro de los propios estados que en una hipótesis de mera ejecución no se plantearían. El TEDH no ejercería, pues, ni su función tuitiva ni contramayoritaria lo que es un ataque a la línea de flotación del sistema.

140 Ley Orgánica $7 / 2015$, de 21 de julio, por la que se modifica la Ley Orgánica 6/1985, de 1 de julio, del Poder Judicial. Concretamente se establece en el artículo 5 bis): «Se podrá interponer recurso de revisión ante el Tribunal Supremo contra una resolución judicial firme, con arreglo a las normas procesales de cada orden jurisdiccional, cuando el Tribunal Europeo de Derechos Humanos haya declarado que dicha resolución ha sido dictada en violación de alguno de los derechos reconocidos en el Convenio Europeo para la Protección de los Derechos Humanos y Libertades Fundamentales y sus Protocolos, siempre que la violación, por su naturaleza y gravedad, entrañe efectos que persistan y no puedan cesar de ningún otro modo que no sea mediante esta revisión». La reforma se justifica en la Exposición de Exposición de Motivos con una curiosa referencia (a juicio de este intérprete) a la seguridad jurídica: «Se incluye, también, una previsión respecto de las sentencias del Tribunal Europeo de Derechos Humanos que declaren la vulneración de alguno de los derechos reconocidos en el Convenio Europeo para la protección de los Derechos Humanos y Libertades Fundamentales y en sus Protocolos, estableciéndose que serán motivo suficiente para la interposición del recurso de revisión exclusivamente de la sentencia firme recaída en el proceso «a quo». Con ello se incrementa, sin lugar a dudas, la seguridad jurídica en un sector tan sensible como el de la protección de los derechos fundamentales, fundamento del orden político y de la paz social, como proclama el artículo 10.1 de nuestra Constitución».

141 Que ya el TC había considerado idóneo para que las sentencias del TEDH fueran ejecutadas, cfr. STC 240/2005 FJ 6: «(...)Desde esta perspectiva, una interpretación del art. 954.4 LECriminal que excluya la subsunción de una Sentencia del Tribunal Europeo de Derechos Humanos de este tipo en el concepto de «hecho nuevo» se opone al principio de interpretación pro actione tal como lo hemos definido anteriormente, ya que se trata de una decisión declara desproporción entre los fines que las causas de inadmisión preservan —especialmente la seguridad jurídica que deriva de la intangibilidad de las Sentencias firmes_ - y los intereses que sacrifican, que en este caso es, ni más ni menos, que un derecho fundamental como el derecho a la presunción de inocencia proclamado en elart. 24.2 CE. No cabe duda de que una declaración como la contenida en la Sentencia ahora invocada del TEDH puede en hipótesis evidenciar «la equivocación de un fallo» condenatorio de personas distintas a las beneficiadas por aquella declaración, por lo que parece evidente que, frente a esta declaración no puede prevalecer «el efecto preclusivo de la Sentencia condenatoria...» (STC 150/1997, F. 5). Para evitar este resultado contrario a la Constitución debe entenderse que, con la incorporación a nuestro ordenamiento de la jurisdicción del Tribunal Europeo de Derechos Humanos, la expresión «hechos nuevos, que evidencien la inocencia del condenado» del art. 954.4 LECriminal, debe interpretarse de modo que en él se incluyan las declaraciones de dicho Tribunal que puedan afectar a procedimientos distintos a 
solución no clausura completamente los problemas y, en especial, está por ver cómo se determina cuando la grave violación de los derechos reconocidos por el Convenio entraña efectos que persistan ${ }^{142}$. En especial, ya hemos señalado que la sentencia de cualquier tribunal que determine la lesión de un derecho fundamental debe perseguir la restitutio in integrum (y la satisfacción equitativa no debe entenderse como una alternativa cuando la restitución integral es posible $)^{143}$. De otra parte, la posición del Tribunal constitucional tampoco resulta debidamente clarificada en el nuevo sistema ${ }^{144}$ Nada dice la LOTC (y el Tribunal ha señalado claramente que no tiene ninguna potestad de intervención cuando la CE o su ley orgánica no se la atribuyan). ¿Qué hacer, por tanto, cuando sea la sentencia del TC la que ha violado uno de los derechos del Convenio? ${ }^{145}$ En cualquier caso en tanto que solución que contiene el revival del soberanismo ha de ser saludada. Efectivamente ya contamos con un mecanismo específico para la ejecución de las sentencias condenatorias. Teniendo ya un instrumento concreto que no da alas a ninguna reluctancia, las reacciones sociales a las sentencias condenatorias se moverán en el terreno del desacuerdo completo (en el ámbito emocional y simbólico) ${ }^{146}$ pero no instarán a la desobediencia como estrategia concreta y posible (por contraria al ordenamiento).

No me parece que pueda concluirse este trabajo sin mencionar que es posible que comencemos a entrar en una nueva e inestable fase en la que las relaciones entre el Reino de España y el TEDH puedan verse afectadas de forma negativa. Y es que, en efecto, el proceso secesionista catalán va a hacer su aparición en Estrasburgo y con él cuestiones altamente sensibles (la forma de entender y proteger la integridad territorial de un estado; el modo particular en qué cada estado traba las relaciones entre Estado de Derecho y Estado democrático; la independencia del poder judicial; el

aquellos en los que tiene origen dicha declaración....». Pérez Tremps, en el Voto Particular a la STC 196/2006 (Punto 5) considera que este pasaje no constituye doctrina sino un obiter dicta.

142 Piénsese en que ésta es una de las cuestiones debatidas en el caso Fuentes Bobo (STC 197/2006). Cfr. en especial, el voto particular del Magistrado Pérez Tremps.

143 No deja de resultarme extraño ese pasaje del Informe del Consejo de Estado sobre la inserción del derecho europeo en el que se señala: «La ausencia de ejecutividad de las sentencias del Tribunal y la previsión de una satisfacción equitativa como mecanismo subsidiario de reparación ha llevado a que algunos países —entre ellos España- no hayan introducido en su derecho interno mecanismos de ejecución ad hoc». p. 296. ¿Se asume como explicación suficiente que España no estableció hasta el año 2015 un mecanismo específico porque lo que pretendía era saldar sus cuentas con el Convenio con el solo pago de la satisfacción equitativa?

144 C. Montesinos Padilla, «El recurso de revisión como cauce de ejecución de las sentencias del Tribunal de Estrasburgo: pasado, presente y futuro», op. cit., p. 109.

145 Ciertamente el hecho de que el Tribunal constitucional sea un remedio subsidiario hace que en la mayoría de los supuestos sean las sentencias de los tribunales ordinarios las responsables directas de la lesión. En algunos casos, no obstante, puede ser el constitucional el único al que quepa imputar la lesión (cfr, por ejemplo, si la lesión se produce en el seno de un proceso de control de constitucionalidad de una ley singular, como en el caso RUMASA; o en los supuestos de recursos directos ante el TC como los del artículo 42 LOTC). Seguramente la tendencia actual, según la cual una buena parte de las condenas a España no han pasado el corte de la trascendencia constitucional en el Tribunal permita a éste ponerse de perfil en este sentido. Pero también es verdad que difícilmente el TC podrá seguir diciendo que «nada de lo que afecte a los derechos fundamentales puede serle ajeno» (STC 245/1991). Acerca del cambio en las relaciones entre TC y TEDH puede verse S. RIPOL CaRULLA, «Un nuevo marco de relación entre el Tribunal Constitucional y el Tribunal Europeo de Derechos Humanos», REDI, vol. LXVI (2014), 1, pp. 11-53.

146 Así han de verse las reacciones en ciertos sectores frente a la sentencia sobre la quema del retrato de los Reyes. http://www.abc.es/opinion/abci-quemados-foto-201803161621_noticia.html 
alcance del derecho a la libertad personal y la prisión como medida cautelar; las exigencias de la participación en procesos electorales...). No es difícil prever la prueba de fuego a la que se va a someter tanto al Tribunal Europeo como a España, muy probablemente, después. Y como el espíritu de la Declaración de La Haya (que el 6 de mayo habrá cumplido 70 años) debe seguir vivo en un Tribunal que vele por un orden constitucional europeo en materia de derechos fundamentales sería más que conveniente proceder a incluir en una eventual reforma de la Constitución española una serie de referencias relativas a la posición del Convenio así como a la obligatoriedad del cumplimiento de sus sentencias. Toda la construcción elaborada solo se mantendrá firme sobre un sustrato de confianza en la legitimidad tanto del Convenio como, sobre todo, del Tribunal. La mejor forma de asegurar esta legitimidad es emplazarla explícitamente en la fuente que todavía mejor representa la imagen que la sociedad quiere tener de sí misma: la Constitución interna ${ }^{147}$.

TITLE: Implementing ECHR judgments in Spain. An European constitutional law approach.

ABSTRACT: This paper studies the execution in Spain of the judgments of the European Court of Human Rights from the perspective of Constitutional Law, more specifically from the perspective of the European Constitutional Law. This begins by pointing out the substantially constitutional quality that both the Convention and the Court have acquired in an ordinamental framework characterized by the principle of subsidiarity as the optimal instrument for guaranteeing both the normative text and the judgments. From this we can deduce a treatment of the latter that puts the emphasis on the obligatory nature of its fulfillment. This is the meaning of the ECtHR jurisprudence so that it has been possible to speak of the distortion of the declaratory nature of its resolutions. Considering the constitutional nature of the ECHR and the ECtHR, and given the need to ensure the effectiveness of its doctrine to guarantee rights, it is focused on the Spanish internal constitutional order, understanding that it is the right to effective judicial protection (ex Article 24) as the right of having judgments executed that makes necessary a specific procedure like the one finally established in the LO 7/2015.

RESUMEN: En este trabajo se aborda la ejecución de las sentencias del TEDH desde la perspectiva del Derecho constitucional, más concretamente del Derecho constitucional europeo. Se comienza así señalando la cualidad sustancialmente constitucional que han adquirido el Convenio Europeo de Derechos Humanos y el Tribunal de Estrasburgo en un marco ordinamental caracterizado por la subsisidiariedad como instrumento óptimo para la garantía tanto del texto normativo como de las sentencias de su guardián. De aquí se deduce un tratamiento de estas últimas que pone el énfasis

147 Ya señalaba este aspecto F. Álvarez-Ossorio MiCHeO, «Los derechos fundamentales», en P. Cruz Villalón (coord.), Hacia la europeización de la Constitución española. La adaptación de la Constitución española al marco constitucional de la Unión Europea, Fundación BBVA, Bilbao, 2006, pp. 75-108. Cfr. tb. B. AlaEz, «se debe trasladar explícitamente una parte de la competencia sobre las competencias (tanto en su faceta de reforma constitucional, como en su faceta de interpretación constitucional) al Derecho de la Unión Europea y a los tratados internacionales sobre Derechos Humanos, sin con ello convertirlos en normas supra-constitucionales que vinculen incluso al poder de reforma constitucional del pueblo español, sino únicamente en normas constitucionales, bajo reserva de que respeten los principios y valores fundamentales del ordenamiento constitucional español, tal y como los interpreta el Tribunal Constitucional. Con dicha reforma constitucional, la globalización material que se deriva de la apertura interpretativa del art. 10.2 CE cambiaría parcialmente de sentido, puesto que ahora sí que habría de conferir a dichos tratados internacionales sobre Derechos Humanos y a las interpretaciones auténticas de los mismos la función constitucionalmente definitoria - y no solo interpretativa — de los derechos fundamentales reconocidos por la CE, dado el expreso rango constitucional de aquéllos, aunque dicha definición se pueda subordinar al respeto a los valores y principios fundamentales del sistema constitucional español bajo un polimorfismo constitucional no equivalente». B. Alaez Corral, «Globalización jurídica desde la perspectiva del Derecho constitucional español», Teoría y realidad constitucional, n. ${ }^{\circ} 40,2017$, p. 276. 
en la obligatoriedad de su cumplimiento. Éste es el sentido de la jurisprudencia del TEDH de modo que se ha podido hablar de la distorsión del carácter declarativo de sus resoluciones. Considerando el carácter constitucional del CEDH $y$ del TEDH, y dada la necesidad de asegurar la eficacia de su doctrina para garantizar los derechos, se repara en el ordenamiento constitucional interno español entendiendo que es el derecho a la tutela judicial efectiva (ex art. 24) como derecho a la ejecución de lo juzgado el que hace necesario un procedimiento específico como el que se establece finalmente en la LO $7 / 2015$.

KEY WORDS: ECHR, EctHR, Implementation of judgments, Constitution, Constitutional Court, Spain.

Palabras clave: CEDH, STEDH, Ejecución de sentencias, Constitución, Tribunal constitucional, España.

FECHA DE RECEPCIÓN: 15.05.2018 FECHA DE ACEPTACIÓN: 13.09.2018 